\title{
Análise comparativa da concentração industrial e de turnover da indústria farmacêutica no Brasil para os segmentos de medicamentos de marca e genéricos ${ }^{1}$
}

\author{
Gerson Rosenberg ${ }^{2}$ \\ Maria da Graça Derengowski Fonseca ${ }^{3}$ \\ Luiz, Antonio d' Avila ${ }^{4}$
}

\section{Resumo}

Este artigo analisa a evolução da estrutura do segmento de medicamentos de marca e genéricos no Brasil a partir de 1997. Após a entrada dos medicamentos genéricos, constatou-se que não houve diminuição significativa da concentração na indústria farmacêutica brasileira, porém, o mesmo não ocorreu em nível mundial, verificando-se um aumento da concentração a partir de 2001, impulsionado pelo expressivo processo de fusões e aquisições nos últimos anos da década de 1990. Em relação ao turnover, notou-se que este foi muito baixo para o grupo das maiores empresas em ambos os segmentos de medicamentos. Entretanto, observa-se um elevado turnover com a entrada dos genéricos, mostrando o fortalecimento da indústria nacional. Verifica-se que o processo de fusões e aquisições entre empresas nacionais é pouco significativo, o que pode ser uma alternativa para as pequenas empresas farmacêuticas aumentarem a sua participação no mercado brasileiro.

Palavras-chave: Indústria farmacêutica - Brasil; Medicamentos genéricos; Fusões e aquisições.

\section{Abstract \\ Comparative analysis of the industrial concentration and turnover of the pharmaceutical industry in Brazil for the segments of mark and generic drugs}

This paper analyzes the evolution of brand-name and generic drugs structure in Brazil since 1997. After the introduction of generic drugs it was not verified a significant decrease in the concentration of Brazilian pharmaceutical industry. The process of mergers and acquisitions in the 90's enhanced the process of concentration in the international market. However, a non-expressive turnover can be demonstrated in both pharmaceutical and generic markets. At the same time, the entrance of the generic industry in Brazil explains the invigoration of the national industry. The mergers and acquisitions process in the pharmaceutical industry is quite intense in Europe and in the USA, although in Brazil it is still not significant.

Key words: Pharmaceutical industry; Generic drugs; Mergers and acquisitions. JEL L100.

(1) Trabalho recebido em agosto de 2007 e aprovado em outubro de 2008.

(2) Tecnologista em Saúde Pública da Fundação Oswaldo Cruz (Fiocruz/MS), Rio de Janeiro, RJ, Brasil. E-mail: <gerson@fiocruz.br>.

(3) Professora do Instituto de Economia da Universidade Federal do Rio de Janeiro (IE/UFRJ), Rio de Janeiro, RJ, Brasil. E-mail: <derengow@ie.ufrj.br>.

(4) Professor da Escola de Química da Universidade Federal do Rio de Janeiro (EQ/UFRJ), Rio de Janeiro, RJ, Brasil. E-mail: < $\underline{\text { davila@eq.ufrj.br }>\text {. }}$ 


\section{Introdução: definições e classificações dos medicamentos}

Um medicamento é uma fórmula farmacêutica acabada, contendo um princípio ativo ou fármaco e é apresentado de várias formas: cápsula, líquido, injetável, pomada, comprimido e outras. Os medicamentos são comercializados de acordo com a sua classe terapêutica e podem ser classificados basicamente em quatro tipos: os de referência - também chamados de medicamentos de marca - os similares, os me toos e os medicamentos genéricos. Os primeiros trazem a marca de seu fabricante e são comercializados com medicamentos que são quase substitutos perfeitos, mas que possuem marcas diferentes das de outros fabricantes. Além disso, os medicamentos de marca competem com medicamentos genéricos que possuem o mesmo princípio ativo ou com aqueles que, como o nome indica, são similares. Os medicamentos de marca são comercializados há mais tempo e foram, em algum momento, considerados novidade, por serem realmente novos do ponto de vista químico ou por pertencerem a uma nova classe terapêutica.

Os medicamentos de marca geralmente exigem grandes investimentos em P\&D e geralmente estão associados a patentes. Adicionalmente, produtos farmacêuticos precisam ser reconhecidos pelos órgãos reguladores que estabelecem rigoroso controle sobre sua segurança, eficácia, qualidade e biodisponibilidade. No caso do Brasil, o órgão regulador é a Anvisa (Agência Nacional de Vigilância Sanitária). Cabe ressaltar que, quando o medicamento novo ou de referência não possui registro no país, a Anvisa considera como referência o produto líder de mercado, desde que sejam comprovados a sua eficácia, segurança e padrões de qualidade. ${ }^{5}$

Os novos medicamentos são inicialmente difundidos por médicos que, em tese, receberiam as informações básicas sobre os mesmos, receitando-os a seus pacientes, tornando, assim, a marca conhecida. A difusão de um medicamento também é facilitada por campanhas publicitárias de divulgação de novos produtos. Esta estratégia pode aumentar o poder de mercado das empresas e, dados os custos das campanhas publicitárias, representa mais um tipo de barreira à entrada de novos concorrentes no segmento de mercado relevante (Frenkel, 2001), como aconteceu no caso do Viagra pela Pfizer.

Os medicamentos de referência podem ser substituídos por produtos similares ou pelos chamados me toos. Os produtos similares são cópias, tanto do ponto de vista químico quanto da classe terapêutica, dos medicamentos de referência. No caso do Brasil, são produzidos por laboratórios que não possuem capacidade de inovar. Os medicamentos chamados de me toos são produtos novos, porém lançados em data posterior à do medicamento de referência ou original.

(5) Disponível em: <http://www.anvisa.gov.br/hotsite/genericos/profissionais/conceitos.htm\#13 $>$. Acesso em: 18 jun. 2007. 
Ainda assim, trata-se de uma inovação, pois apresenta estrutura molecular distinta à do medicamento de referência, sendo, portanto, quimicamente diferente, apesar de possuir atividade terapêutica semelhante. Na realidade, trata-se de uma inovação incremental, se comparada tecnologicamente com os produtos originalmente inovadores, mas pode também oferecer melhorias incrementais em nível terapêutico, como no caso dos remédios que reduzem os efeitos colaterais dos originais. As empresas que produzem me toos evitam competir diretamente em termos de preços com o produto de referência, mas procuram captar uma parcela do mercado aberto por este último, diferenciando-se do mesmo. ${ }^{6}$

Os produtos genéricos são assim designados porque são comercializados pela denominação genérica ${ }^{7}$ do fármaco e não por uma marca própria. Assim, este produto é igual ou comparável ao de referência (ou inovador, ou original, ou de marca) em quantidade de princípio ativo, concentração, forma farmacêutica, modo de administração e qualidade, e pretende ser com ele intercambiável. Os genéricos sãos produzidos após expiração ou renúncia da patente e de direitos de exclusividade dos medicamentos que lhe servem de referência. A lei brasileira obriga que os medicamentos genéricos sejam submetidos a critérios de eficácia, segurança e qualidade através de testes de biodisponibilidade e bioequivalência terapêutica. Mas ao contrário dos fabricantes de medicamentos de marca, os fabricantes de medicamentos genéricos não têm necessidade de difundir seu produto junto aos médicos pelo fato de não estarem associados a uma marca - seja de um medicamento genérico, seja de um similar - o que reduz sensivelmente os gastos com propaganda. Desta forma, o consumidor pode selecionar o produto mais barato na farmácia sem necessitar de uma nova prescrição terapêutica, cabendo ao farmacêutico a responsabilidade direta pela sua difusão no mercado.

Aparentemente, as empresas líderes do setor farmacêutico estão buscando cada vez mais aumentar sua participação no mercado através de duas estratégias. Em primeiro lugar, e como é característico da indústria farmacêutica, a liderança no mercado exige o lançamento de produtos inovadores, de preferência apoiados em patentes. Além disso, é necessário realizar grandes gastos em $\mathrm{P} \& \mathrm{D}$, mas também grandes gastos anuais em marketing para que as empresas líderes possam sustentar a competição com seus rivais em termos de vendas. Desta forma, as corporações farmacêuticas procuram lançar produtos que garantam a liderança definida de suas megamarcas - ou megabrands, como denominados pela AstraZeneca em 1999. Estes lançamentos procurariam assegurar aos proprietários destas marcas ${ }^{8}$ : (i) alcançar US\$ 1 bilhão em vendas anuais antes de dois anos

(6) Disponível em: <http://www.anvisa.gov.br/hotsite/genericos/profissionais/conceitos.htm\#13 $>$. Acesso em: 18 jan. 2007.

(7) Denominação genérica é o nome de aceitação universal para o medicamento, usado para distinguir um princípio ativo não amparado por marca comercial ou patente. Disponível em: <http://www.anvisa.gov.br/hotsite/genericos/profissionais/conceitos.htm\#13 >. Acesso em: 18 jun. 2007.

(8) McKillop (1999). Disponível em: <http://www.ims-global.com>. Acesso em: 18 jan. 2007. 
após o lançamento, garantindo o faturamento de vários bilhões de dólares; (ii) ser comercializado num grande grupo de países - pelo menos 60, segundo a AstraZeneca - num período inicial de dois anos e (iii) ser apoiado por investimentos em torno da megamarca, no mínimo proporcional ao que gastam seus principais rivais. Segundo a AstraZeneca, isso significaria algo entre US\$ 450 milhões e US\$ 1 bilhão nos primeiros dois anos de lançamento, sendo que os gastos no pré-lançamento mais o custo do desenvolvimento representariam $25 \%$ deste total. Apesar disso, o risco comercial associado aos lançamentos é bastante significativo, o que sugere que só as grandes companhias podem participar. ${ }^{9}$ Em segundo lugar, e à medida que as patentes vão se aproximando do seu prazo limite, os proprietários das megamarcas passam a atuar também no mercado de produtos genéricos.

\section{Análise da competição do setor farmacêutico}

Os fatores que determinam a competição na indústria farmacêutica são vários. Do ponto de vista da estrutura de mercado, pode-se apontar: a diferenciação de produtos por meio de classes terapêuticas e as estratégias de promoção e marketing a partir das marcas, elevados investimentos em pesquisa e desenvolvimento (P\&D), integração vertical e, last but not least, as patentes. Estas características constituem barreiras à entrada de novos competidores no mercado. Do ponto de vista estratégico, destacam-se as diferentes políticas de preços, especialmente após o aparecimento dos medicamentos genéricos, e as estratégias de fusões e aquisições, que caracterizaram a indústria, especialmente no final dos anos 1990 (Queiroz, 1993; Sherer, 2000; Unicamp, 2000; Frenkel, 2002; Hasenclever, 2002; Derengowski et al., 2005). ${ }^{10} \mathrm{O}$ presente artigo enfatiza o estudo das características da concorrência entre fabricantes de medicamentos, destacando a análise do grau de concentração, das estratégias de diferenciação de produtos e de fusões e aquisições, concluindo com um exame do turnover para os mercados de medicamentos de marca e de genéricos no Brasil e no mundo.

O poder de mercado das empresas líderes da indústria farmacêutica manifesta-se tanto em função do grau de concentração do mercado por classe terapêutica quanto da capacidade de diferenciação das empresas farmacêuticas. A noção de diferenciação do produto está relacionada à possibilidade de investir altas somas no desenvolvimento de novos produtos e no marketing promocional em torno das megamarcas. A concentração industrial é a dimensão da estrutura de

(9) A AstraZeneca possui as seguintes megabrands comercializadas: Nexium (esomeprazole), Viozan, Crestor, e o Iressa. Entre outras megabrands, pode-se citar o Lipitor e o Norvasc da Pfizer, bem como o Prozac da Eli Lilly. Disponível em: <http://www.ims-global.com>. Acesso em: 18 jan. 2007.

(10) Diversos estudos apontam que a estrutura típica do mercado farmacêutico pode ser caracterizada como de oligopólio diferenciado, em função não só da existência de diversas classes terapêuticas, mas também das estratégias de diferenciação de produtos, o que se manifesta através de campanhas de vendas e adoção de marcas (Scherer, 2000, p. 1320). 
mercado que, na literatura especializada sobre competição na indústria farmacêutica, tem recebido tratamento mais amplo e detalhado. A intensidade e a efetividade da competição são significativamente afetadas pelo grau de concentração de ofertantes em um determinado mercado (Bain, 1968, p. 126). Os índices de concentração devem possuir as seguintes características (Hall; Tideman, 1967; Curry; George, 1983; Hay; Morris, 1991, p. 208): (i) a concentração deve possuir uma só dimensão e ser independente do tamanho da indústria; (ii) a concentração deve aumentar se os consumidores mudarem das pequenas firmas para as grandes, e vice-versa; (iii) ceteris paribus, ${ }^{11}$ a entrada de novas firmas, com tamanho menor que a média das firmas existentes, deve reduzir a concentração; (iv) as fusões devem causar aumento da concentração. Assim, a preocupação no estabelecimento de um índice deve ser com o número de empresas e a desigualdade de tamanho entre elas.

No tocante às barreiras à entrada, a manutenção das posições das empresas farmacêuticas no mercado, sem serem deslocadas por concorrentes, pode ser reflexo de barreiras elevadas, enquanto que mercados em que haja trocas intensas de posição entre as empresas estariam associados a menores barreiras e, portanto, menor poder de mercado. Neste contexto, o grau com que as empresas mudam de posição ao longo do tempo dá uma ideia da existência de barreiras à entrada e do poder de mercado das empresas.

A competição do setor farmacêutico ocorre principalmente através da diferenciação de produtos, com os grandes laboratórios multinacionais aumentando crescentemente seus gastos com Pesquisa e Desenvolvimento (P\&D) e marketing como forma de garantir a manutenção das suas vendas. $O$ desenvolvimento de novas moléculas tem como finalidade o lançamento de novas marcas no mercado sob diferentes tipos de apresentações, enquanto a diferenciação através da propaganda exige a divulgação da marca junto ao médico e ao consumidor final. Logo, a oferta de medicamentos está relacionada ao desenvolvimento de novas substâncias, cuja pesquisa é de alto risco para os fabricantes.

Nos EUA, os gastos em P\&D das companhias farmacêuticas americanas aumentaram de US\$ 262 milhões em 1951 para US\$ 1,7 bilhão em 1967, US\$ 3,1 bilhões em 1980 e US\$ 8 bilhões, mantendo o preço constante, em 1990 (Scherer In: Culyer; Newhouse, 2000, p. 1307). Segundo DiMasi et al. (2003, p. 167) os gastos totais em P\&D em 2000 para um novo medicamento seria da ordem de 802 milhões de dólares, considerando-se que a etapa pré-clínica representava 41,8\% dos gastos em P\&D. Em 2003, a empresa líder mundial Pfizer investiu 18\% das

(11) Assumindo que a participação das demais firmas no mercado continue inalterada, os dois indicadores mais usados para medir a concentração industrial são: Índice da Concentração Simples ou Razão da Concentração (CR) e o Índice de Hirschman-Herfindahl (HHi). 
vendas, que totalizaram em US\$ 39.631 bilhões, em P\&D, enquanto as demais empresas investiram em média 17,4\% (Scrip's 2005 Yearbook, 2005). As recentes despesas das empresas com propaganda também mostraram um grande aumento, em pouco espaço de tempo, com gastos da ordem de 800 milhões de dólares em 1996, elevando-se posteriormente para 1,35 bilhão de dólares em 1998, ou seja, um aumento de $69 \%$ em dois anos. ${ }^{12}$ Em 2002, verifica-se um gasto total de 19,1 bilhões de dólares em marketing, sendo 2,7 bilhões de dólares em promoção junto a hospitais e com anúncios em jornais, o direct-to-consumer. ${ }^{13}$

Quando a patente expira, uma nova competição surge com os medicamentos genéricos em que, normalmente, pouca ou nenhuma propaganda é feita. A extensão pela qual os medicamentos genéricos são substitutos dos medicamentos de marca originais e seus impactos sobre os preços varia de país para país e também através da classe terapêutica (Scherer, 2000, p. 1321). A tendência é que cada vez mais aumente a concorrência pelos medicamentos genéricos devido ao fato de, nos países desenvolvidos, o consumo de medicamentos e de serviços de saúde ter crescido a taxas elevadas, em decorrência do envelhecimento da população, do aumento das doenças crônicas e da disseminação de novas e custosas tecnologias médicas.

A partir dos anos 1990 os gastos com saúde em relação ao PIB aumentaram consideravelmente nos países desenvolvidos, gerando medidas governamentais para reduzir os custos dos medicamentos por meio de políticas regulatórias do setor (Rêgo, 2000). Além disso, tanto na Europa como nos EUA, as organizações privadas de assistência farmacêutica, conhecidas como Pharmaceutical Benefit Managements (PBMs) e Health Maintenance Organizations (HMOs), também se fortaleceram com a busca da redução dos preços dos medicamentos, quer seja pela negociação direta com os fabricantes quer seja pelo aumento da substituição dos medicamentos de marca pelos genéricos (Scherer, 2004).

Entre as principais características estruturais da indústria farmacêutica internacional destacam-se: grande integração vertical em direção à produção dos princípios ativos (farmoquímica); aumento das economias de escala por meio da construção de plantas de maior complexidade tecnológica; desenvolvimento de novas moléculas em parceria com empresas intensivas em $P \& D$ na área de biotecnologia, superando as rotas tecnológicas da síntese química, e intensificação do processo de diferenciação de produto através do lançamento de novos medicamentos em classes terapêuticas mais comercializadas. As estratégias recentes das empresas são: instalação de centros de $\mathrm{P} \& \mathrm{D}$ em países em

(12) Disponível em: <http://www.fda.gov/cder/ddmac/P2schultz/sld003.htm>. Acesso em: 2 jan. 2007.

(13) Disponível em: <http://www.fda.gov/cder/ddmac/p4masia/sld002.htm>. Acesso em: 2 jan. 2007. 
desenvolvimento (Índia e China); estratégias que impedem o lançamento de medicamentos genéricos através de ações legais ou pela fabricação de seus próprios genéricos; aumento do número de aquisições e fusões e manutenção das elevadas margens de lucro da indústria (Scherer, 2004).

No Brasil as mudanças regulatórias e econômicas ocorridas na década de 1990 também propiciaram estratégias de crescimento das empresas farmacêuticas atuantes no país. Entre as principais mudanças, pode-se citar: redução da proteção tarifária e das barreiras não tarifárias; estabilização da moeda; política cambial flexível; controle da inflação; criação da agência reguladora para o setor (Anvisa); desmonte dos mecanismos de controle de preços; ${ }^{14}$ promulgação da Lei sobre Patentes; introdução dos medicamentos genéricos e a imposição de novas regras ao setor industrial com o intuito de garantir a qualidade dos medicamentos comercializados no país.

\subsection{Concentração da indústria de farmacêutica no Brasil}

O número de empresas farmacêuticas nacionais atuando no mercado brasileiro, em 2005 , representa $71 \%$ do total das empresas, conforme mostra a Figura 1.

Figura 1

Origem das empresas que atuam no mercado brasileiro
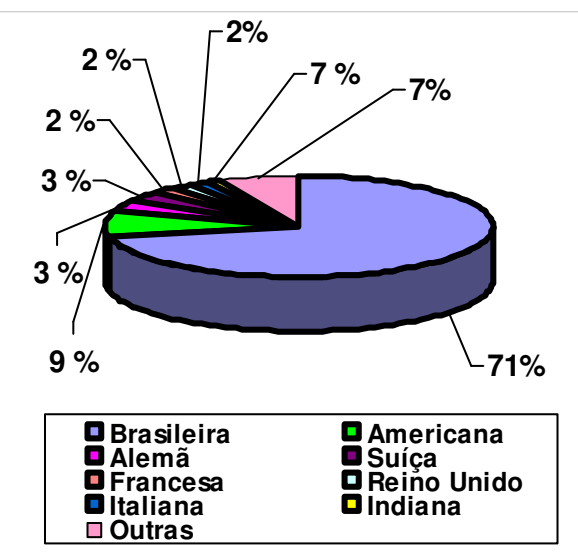

Fonte: Elaboração própria a partir das informações obtidas no IMS do Brasil (2006). Disponível em: <http://www.imshealth.com.br/>. Acesso em: 15 maio 2006.
Figura 2

Percentual de vendas das empresas que atuam no mercado brasileiro

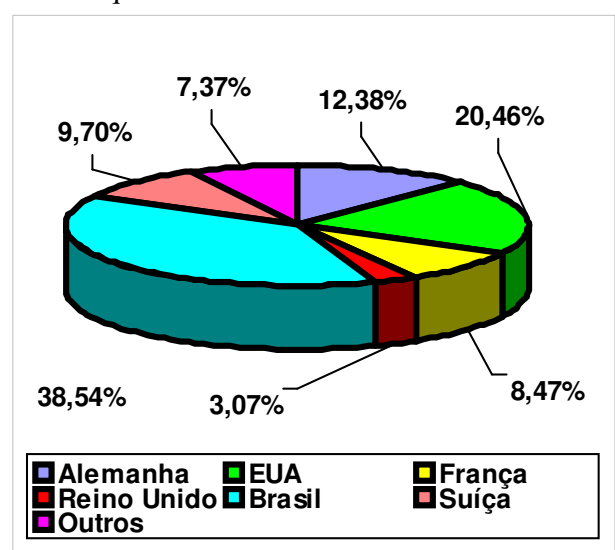

Fonte: Elaboração própria a partir das informações obtidas no IMS do Brasil (2006).

(14) No Brasil, entre 1997 e 2001, não houve controle de preços dos medicamentos. Atualmente o controle de preços é feito pela Câmara de Regulação do Mercado de Medicamentos - CMED, que tem entre as suas principais funções a regulamentação do mercado e o estabelecimento de critérios para definição e ajuste de preços. Disponível em: <http://www.anvisa.gov.br/monitora/cmed/index.htm>. Acesso em: 10 set. 2006. 
Em termos de vendas, 38,5\% das empresas, em 2005, são nacionais. Entre as multinacionais destacam-se as empresas americanas, que possuem $20,5 \%$ do mercado interno, conforme mostra a Figura 2.

Observa-se, no Quadro 1, que no período entre 1997 e 2005 não existe quase nenhuma mudança nos posicionamentos das cinco primeiras empresas do setor, que são: Sanofi-Aventis, Aché, Novartis, Pfizer e Roche. Cabe ressaltar que a liderança da Sanofi-Aventis entre as cinco primeiras é explicada pela a fusão das empresas Hoechst Marion Roussel (Alemanha) e a Rhône-Poulenc (França) e da Rhodia Farma (Brasil), formando a Aventis Pharma em 1999, e depois pela nova fusão com a empresa Sanofi-Synthelabo em 2004.

Embora a empresa Pfizer tenha feito duas fusões neste período, sendo a primeira com a Warner-Lambert Corp. em 2000 e a segunda com a Pharmacia Corporation em 2003, sua liderança também pode ser atribuída ao sucesso do medicamento Viagra que alcançou a cifra de R\$ 200 milhões em 2003, destacando-se como líder de vendas até 2005. As outras três empresas também fizeram aquisições neste período. As cinco empresas praticamente não alteraram sua posição no ranking setorial, com percentuais bem definidos ao longo destes nove anos, conforme mostra o Quadro 1. Houve uma pequena mudança no ranking setorial no período entre 2004 e 2005, quando a empresa nacional Aché passou a liderar o setor com uma participação média de 6,0 \% do mercado farmacêutico.

No Quadro 1, verifica-se que, entre as vinte maiores empresas em 1997, apenas duas eram brasileiras, correspondendo a um market-share de 9,2\%. Entretanto, este quadro se alterou e, nos anos subsequentes, o número de empresas nacionais aumentou sucessivamente, contando, em 2005, com um total de sete empresas brasileiras entre as vinte maiores, o que corresponde a 25,5\% do mercado. Este fato pode ser atribuído principalmente ao início da comercialização dos medicamentos genéricos a partir de 1999. Cabe ressaltar que, em 2005, entre as sete maiores empresas brasileiras do setor farmacêutico, somente a D.M. Ind. Ftca não vendia medicamentos genéricos, embora fosse especializada na comercialização de produtos sem prescrição médica, ou seja, OTC (Over The Counter).

Em 2005, entre as dez maiores do setor farmacêutico, quatro eram empresas nacionais produtoras de medicamentos genéricos: Aché, Medley, Eurofarma e EMS Sigma Pharma. Embora atuando tanto no mercado de genéricos quanto no de marcas, estas empresas possuíam estratégias diferentes de entrada no mercado de genéricos. O Aché foi a única empresa que optou por esperar a consolidação do mercado de genéricos para investir nele, adquirindo, em 2005, a empresa Biosintética, por cerca de R\$ 600 milhões, terceira no ranking de genéricos. As demais usaram suas próprias instalações, em 2000, para iniciarem a produção dos medicamentos genéricos. 
Análise comparativa da concentração industrial e de turnover da indústria farmacêutica no Brasil...

Quadro 1

Ranking das empresas no setor farmacêutico brasileiro em ordem decrescente,

da primeira até a vigésima

\begin{tabular}{|c|c|c|c|c|c|c|c|c|}
\hline Ano 1997 & Ano 1998 & Ano 1999 & Ano 2000 & Ano 2001 & Ano 2002 & Ano 2003 & Ano 2004 & Ano 2005 \\
\hline Ranking & Ranking & Ranking & Ranking & Ranking & Ranking & Ranking & Ranking & Ranking \\
\hline Novartis & Novartis & $\begin{array}{l}\text { Aventis } \\
\text { Pharma }\end{array}$ & Aché & Pfizer & Pfizer & Pfizer & Pfizer & Aché \\
\hline Aché & Aché & Aché & $\begin{array}{l}\text { Aventis } \\
\text { Pharma }\end{array}$ & Aché & Aché & Aché & Aché & $\begin{array}{l}\text { Sanofi } \\
\text { Aventis }\end{array}$ \\
\hline $\begin{array}{l}\text { Hoechst } \\
\text { M. R. }\end{array}$ & $\begin{array}{c}\text { Hoechst } \\
\text { M. R. }\end{array}$ & Novartis & Pfizer & $\begin{array}{l}\text { Aventis } \\
\text { Pharma }\end{array}$ & $\begin{array}{l}\text { Aventis } \\
\text { Pharma }\end{array}$ & $\begin{array}{l}\text { Aventis } \\
\text { Pharma }\end{array}$ & $\begin{array}{l}\text { Aventis } \\
\text { Pharma }\end{array}$ & $E M S$ \\
\hline $\begin{array}{l}\text { Bristol } \\
\text { M. S. }\end{array}$ & $\begin{array}{l}\text { Bristol } \\
\text { M. S. }\end{array}$ & Pfizer & Novartis & Novartis & Novartis & Novartis & Novartis & Pfizer \\
\hline Roche & Roche & Roche & Roche & Roche & Roche & Roche & $E M S$ & Novartis \\
\hline $\begin{array}{l}\text { Schering } \\
\text { Plough }\end{array}$ & $\begin{array}{c}\text { Schering } \\
\text { Plough }\end{array}$ & $\begin{array}{l}\text { Bristol } \\
\text { M. S. }\end{array}$ & $\begin{array}{l}\text { Bristol } \\
\text { M. S. }\end{array}$ & $\begin{array}{c}\text { Schering } \\
\text { Plough }\end{array}$ & $\begin{array}{c}\text { Schering } \\
\text { Plough }\end{array}$ & $E M S$ & Roche & Medley \\
\hline $\begin{array}{l}\text { Janssen } \\
\text { Cilag }\end{array}$ & $\begin{array}{c}\text { Janssen } \\
\text { Cilag }\end{array}$ & $\begin{array}{l}\text { Glaxo } \\
\text { S. K. }\end{array}$ & $\begin{array}{c}\text { Glaxo } \\
\text { S.K. }\end{array}$ & $\begin{array}{l}\text { Bristol } \\
\text { M. S. }\end{array}$ & $E M S$ & $\begin{array}{c}\text { Schering } \\
\text { Plough }\end{array}$ & Medley & $\begin{array}{c}\text { Boehringer } \\
\text { I }\end{array}$ \\
\hline Boehringer & Boehringer & $\begin{array}{c}\text { Merck } \\
\text { S. D. }\end{array}$ & $\begin{array}{l}\text { Merck } \\
\text { S. D. }\end{array}$ & $\begin{array}{c}\text { Janssen } \\
\text { Cilag }\end{array}$ & $\begin{array}{c}\text { Merck } \\
\text { S.D. }\end{array}$ & $\begin{array}{l}\text { Schering } \\
\text { do Brasil }\end{array}$ & $\begin{array}{c}\text { Boehringer } \\
\text { I }\end{array}$ & $\begin{array}{c}\text { Schering } \\
\text { Plough }\end{array}$ \\
\hline $\begin{array}{l}\text { Glaxo } \\
\text { Wellcome }\end{array}$ & Wyeth & $\begin{array}{c}\text { Janssen } \\
\text { Cilag }\end{array}$ & $\begin{array}{c}\text { Schering } \\
\text { Plough }\end{array}$ & $\begin{array}{c}\text { Glaxo } \\
\text { S.K. }\end{array}$ & $\begin{array}{l}\text { Schering } \\
\text { do Brasil }\end{array}$ & $\begin{array}{c}\text { Merck } \\
\text { S. D. }\end{array}$ & $\begin{array}{c}\text { Schering } \\
\text { Plough }\end{array}$ & Eurofarma \\
\hline $\begin{array}{l}\text { Schering } \\
\text { do } \\
\text { Brasil }\end{array}$ & Pfizer & $\begin{array}{c}\text { Schering } \\
\text { Plough }\end{array}$ & $\begin{array}{c}\text { Janssen } \\
\text { Cilag }\end{array}$ & $\begin{array}{c}\text { Merck } \\
\text { S. D. }\end{array}$ & $\begin{array}{c}\text { Janssen } \\
\text { Cilag }\end{array}$ & Medley & $\begin{array}{c}\text { Schering do } \\
\text { Brasil }\end{array}$ & $\begin{array}{c}\text { Schering do } \\
\text { Brasil }\end{array}$ \\
\hline Wyeth & $\begin{array}{c}\text { Glaxo } \\
\text { Wellcome }\end{array}$ & Boehringer & Boehringer & Boehringer & Boehringer & Boehringer & $\begin{array}{c}\text { Merck } \\
\text { S. D. }\end{array}$ & Altana \\
\hline $\begin{array}{l}\text { Merck } \\
\text { S. D. }\end{array}$ & $\begin{array}{c}\text { Schering do } \\
\text { Brasil }\end{array}$ & $\begin{array}{c}\text { Sanofi } \\
\text { Synthelabo }\end{array}$ & $\begin{array}{c}\text { Sanofi } \\
\text { Synthelabo }\end{array}$ & $\begin{array}{c}\text { Schering do } \\
\text { Brasil }\end{array}$ & $\begin{array}{c}\text { Bristol } \\
\text { M. S. }\end{array}$ & $\begin{array}{l}\text { Bristol } \\
\text { M. S. }\end{array}$ & $\begin{array}{l}\text { Bristol } \\
\text { M. S. }\end{array}$ & $\begin{array}{c}\text { Janssen } \\
\text { Cilag }\end{array}$ \\
\hline Lilly & $\begin{array}{l}\text { Merck } \\
\text { S. D. }\end{array}$ & Abbott & $\begin{array}{c}\text { Schering do } \\
\text { Brasil }\end{array}$ & $E M S$ & Medley & $\begin{array}{c}\text { Janssen } \\
\text { Cilag }\end{array}$ & $\begin{array}{c}\text { Janssen } \\
\text { Cilag }\end{array}$ & Roche \\
\hline $\begin{array}{l}\text { Sanofi } \\
\text { Winthrop }\end{array}$ & Lilly & Wyeth & Abbott & Altana & Altana & Altana & Altana & Bayer \\
\hline $\begin{array}{c}\text { S.K. } \\
\text { Beecham }\end{array}$ & $\begin{array}{c}\text { Sanofi } \\
\text { Winthrop }\end{array}$ & Altana & Altana & $\begin{array}{c}\text { Sanofi } \\
\text { Synthelabo }\end{array}$ & $\begin{array}{c}\text { Glaxo } \\
\text { S.K. }\end{array}$ & $\begin{array}{c}\text { Sanofi } \\
\text { Synthelabo }\end{array}$ & Eurofarma & $\begin{array}{c}D M \\
\text { Ind.Ftca }\end{array}$ \\
\hline Pfizer & $\begin{array}{c}\text { S.K. } \\
\text { Beecham }\end{array}$ & $\begin{array}{c}\text { Schering do } \\
\text { Brasil }\end{array}$ & Wyeth & Abbott & $\begin{array}{c}\text { Sanofi } \\
\text { Synthelabo }\end{array}$ & $\begin{array}{c}\text { Glaxo } \\
\text { S.K. }\end{array}$ & $\begin{array}{c}\text { Sanofi } \\
\text { Synthelabo }\end{array}$ & $\begin{array}{l}\text { Merck } \\
\text { S. D. }\end{array}$ \\
\hline Byk ** & Byk & $\begin{array}{c}\text { Astra } \\
\text { Zeneca }\end{array}$ & $\begin{array}{c}D M \\
\text { Ind.Ftca }\end{array}$ & Wyeth & $\begin{array}{c}\text { D M } \\
\text { Ind.Ftca }\end{array}$ & $\begin{array}{c}D M \\
\text { Ind.Ftca }\end{array}$ & $\begin{array}{c}D M \\
\text { Ind.Ftca }\end{array}$ & $\begin{array}{l}\text { Bristol } \\
\text { M.S. }\end{array}$ \\
\hline Rhodia & Rhodia & $\begin{array}{c}D M \\
\text { Ind.Ftca }\end{array}$ & $E M S$ & $\begin{array}{c}D M \\
\text { Ind.Ftca }\end{array}$ & Wyeth & Abbott & $\begin{array}{c}\text { Glaxo } \\
\text { S.K. }\end{array}$ & $\begin{array}{c}\text { Glaxo } \\
\text { S.K. }\end{array}$ \\
\hline Knoll & Knoll & Organon & Organon & Medley & Abbott & Wyeth & Abbott & Libbs \\
\hline Prodome & Prodome ${ }^{*}$ & Farmasa & $\begin{array}{c}\text { Astra } \\
\text { Zeneca }\end{array}$ & Organon & Organon & Eurofarma & Libbs & Abbott \\
\hline
\end{tabular}

Fonte: Elaboração própria a partir dos dados fornecidos pelo IMS Health Brasil em 2006. Legenda: em preto = empresa estrangeira, em itálico = empresa nacional. $\left({ }^{*}\right)$ formada em 1988 joint-venture entre a Merck Sharp \& Dohme Farmacêutica Ltda e a Aché. (**). Em 2002 a Byk mudou de nome para Altana Pharma. 
Na Figura 3, o índice de concentração descrito para o período de 1997 a 2005 revela um aumento, em 1999, do CR(4), CR(8) e CR(20), fato que pode ser atribuído às aquisições e fusões ocorridas entre as grandes empresas farmacêuticas mundiais. O surgimento dos medicamentos genéricos no Brasil não alterou significativamente o índice de concentração industrial do setor farmacêutico, como mostra a Figura 3.

Figura 3

Índice de concentração industrial no setor farmacêutico brasileiro

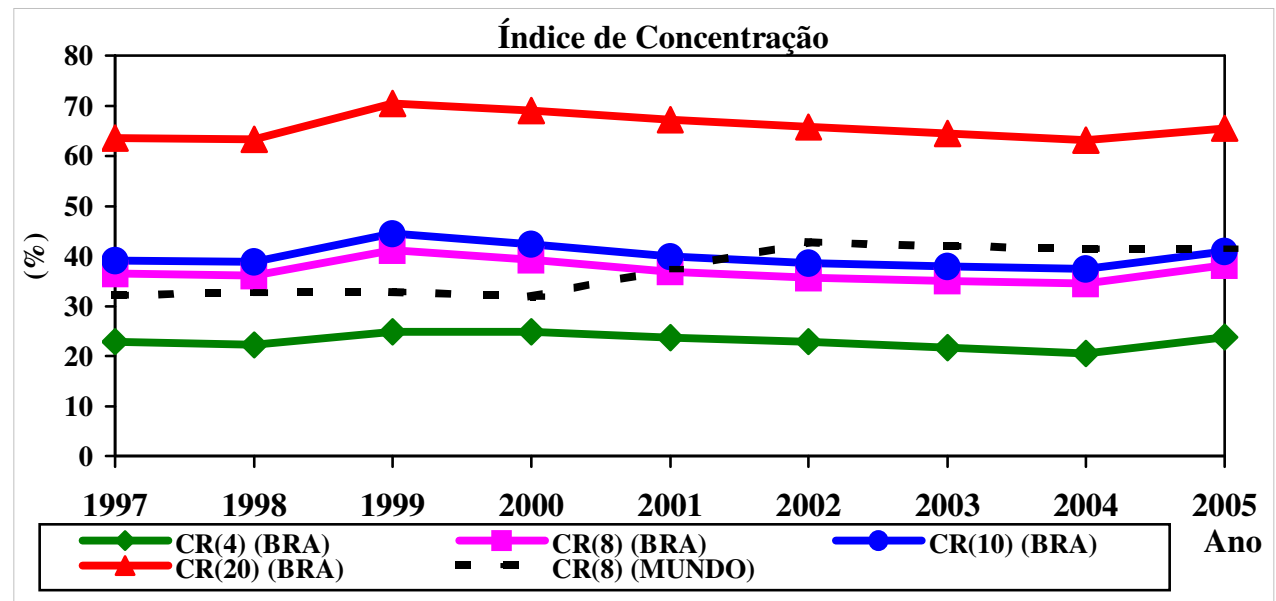

Fonte: Elaboração própria a partir das informações obtidas no IMS do Brasil (2006).

O índice de concentração do setor farmacêutico brasileiro comparado com o mercado farmacêutico americano, que é o maior do mundo, apresenta-se menos oligopolizado, pois o $\mathrm{CR}(4)$ e o $\mathrm{CR}(8)$ divulgados pelo U.S. Department of Commerce $^{15}$ apresentam valores bem maiores: para o ano de 1997, o CR(4) e o CR(8) são de $32,9 \%$ e 49,5 \% e, para o ano de 2003, o CR(4) e o CR(8) são de $34,0 \%$ e $50,0 \%$.

Existe certa semelhança entre o $\mathrm{CR}(8)$ mundial (linha tracejada na Figura 3) e o do Brasil, mostrando que o mercado farmacêutico brasileiro é afetado pelo que ocorre internacionalmente, considerando-se que o mercado mundial farmacêutico está passando por um processo acelerado de concentração no qual, nos últimos quatro anos, os oito maiores grupos, CR (8), elevaram a sua participação no mercado mundial de 32,8 \% em 1999 para 41,5 \% em 2005.

A classificação das agências antitrustes estabelece que o $\mathrm{HH}_{\mathrm{i}}$ acima de1800 merece preocupação quanto à competição, pois são considerados setores com elevado grau de concentração do mercado (Ferguson; Ferguson, 1994, p. 168).

(15) Disponível em: <http://www.census.gov/epcd/www/econ97.html>. Acesso em: 10 jun. 2007. 
Figura 4

Índice $\mathrm{HH}_{\mathrm{i}}$ do setor farmacêutico brasileiro

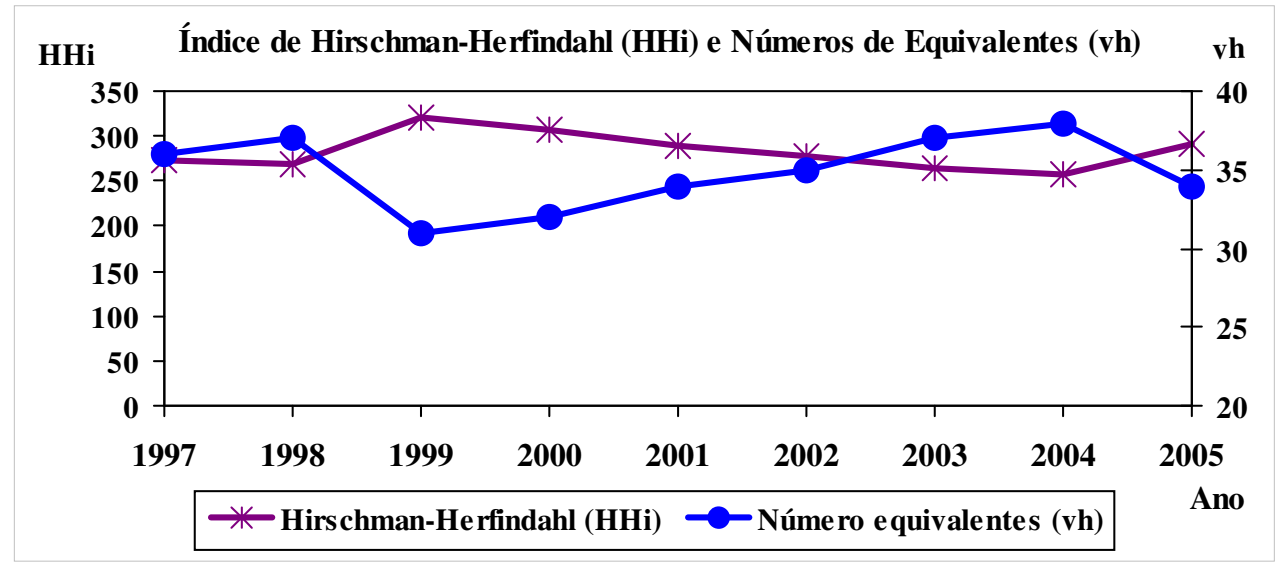

Fonte: Elaboração própria a partir das informações obtidas no IMS do Brasil (2006).

$\mathrm{O}$ índice de concentração calculado por meio do $\mathrm{HH}_{\mathrm{i}}$ mostrou um valor abaixo de $1800\left(\mathrm{HH}_{\mathrm{i}}<1800\right)$ para os anos de 1997 a 2005, conforme apresentado na Figura 4. Desta forma, pode-se classificar o setor farmacêutico brasileiro como de baixa concentração. Existe uma semelhança das curvas $\mathrm{HH}_{\mathrm{i}}$ com as do $\mathrm{CR}$, o que mostra a existência de uma correlação entre os dois índices. $\mathrm{O}$ número de empresas equivalentes $\left(\mathrm{v}_{\mathrm{H}}\right)$ é pequeno e praticamente não se alterou no período analisado, indicando pouco poder concorrencial entre as firmas.

\section{Fusões e aquisições na indústria farmacêutica}

$\mathrm{Na}$ literatura econômica a questão da aquisição e fusões é tratada intensivamente em conexão com estudos sobre monopólio e competição, estrutura de mercado e grau de concentração e, mais recentemente, a relação entre fusão e tamanho do setor tem recebido considerável atenção. Os oligopólios diferenciados se caracterizam pela diversificação das firmas, e isto ocorre devido ao engajamento sistemático nas atividades de $\mathrm{P} \& \mathrm{D}$ em decorrência do padrão de competição vigente nestes mercados, em que se pode usar o domínio de tecnologias aplicáveis a outras indústrias ou mesmo introduzir novos produtos em outros mercados. O obstáculo à diversificação resultante da falta de conhecimento tecnológico requerido pela nova atividade de pesquisa ou da pouca familiaridade com os fatores de competição exigidos pelo novo mercado pode ser vencido através da aquisição ou fusão de algumas das firmas existentes (Guimarães, 1981, p. 67).

Segundo Penrose (1995, p. 1560), existem, em princípio, dois métodos para a expansão de uma firma individualmente, sendo o primeiro a construção de 
uma nova planta e a criação de novos mercados e o segundo, a aquisição de uma planta e atuação no mercado já existente. O processo de expansão de uma firma dentro de um setor oligopolizado para outros mercados nacionais pode ocorrer inicialmente pela aquisição da capacidade instalada de uma firma local, o que permite obter canais de comercialização e forças de vendas já consolidadas. Tal fato ocorreu quando algumas empresas farmacêuticas estrangeiras se instalaram no Brasil nos anos setenta, quando se verificou que vinte laboratórios brasileiros foram adquiridos principalmente por empresas americanas (Valentim, 2003, p. 17).

Historicamente, as grandes empresas farmacêuticas procuraram manter uma lucratividade estável e um crescimento constante por meio de lançamento de novos medicamentos. Entre os anos sessenta e setenta muitas empresas farmacêuticas, com exceção da Merck, adquiriram outras companhias para se diversificarem, formando conglomerados (por exemplo: Pfizer e Lilly adquiriram empresas de cosméticos, Abbott comprou empresas de produtos nutricionais e a American Home Products comprou uma empresa de produtos de limpeza). Investimentos em negócios menos lucrativos permitiram estabilidade e, com isso, equilibraram o risco inerente às descobertas e ao desenvolvimento de novos processos.

As estratégias de diversificação rapidamente se inverteram nos anos oitenta porque os medicamentos de grande sucesso de vendas (chamados de blockbuster drugs) estavam obtendo renda suficiente para sustentar o crescimento corporativo. Este fato, somado aos avanços nas ciências da vida, convenceu os dirigentes das grandes empresas de que deveriam apenas se fixar no negócio farmacêutico. A confiança no P\&D levou a um novo ciclo de fusões e aquisições, bem como joint venture dentro da indústria farmacêutica. $\mathrm{O}$ movimento de fusões e aquisições na indústria farmacêutica mundial dos anos 1990 sugere que buscavam obter economia de escala e escopo principalmente nas atividades de P\&D ${ }^{16}$ (Henderson; Cockburn, 1996; Cohen et al., 2004, p. 11), caracterizando as fusões e aquisições mais do tipo horizontal. Segundo Henderson (2000, p. 2), a partir da metade dos anos 1990, a razão para as operações de fusões e aquisições entre os grandes laboratórios seria a diminuição dos custos de marketing e de distribuição e, principalmente, o aumento do portfolio de seus produtos. Outro fator que contribuiu para as aquisições mais recentes foi o aparecimento, a partir

(16) As empresas farmacêuticas frequentemente requerem substanciais investimentos em custos fixos para realizarem as suas pesquisas, tais como: biblioteca, computadores para pesquisa, grandes equipamentos, entre outros. A economia de escala se dá com a repartição desses recursos sobre uma extensa base de atividades de pesquisa. Já a economia de escopo acontece quando os custos de conduzir duas ou mais atividades de pesquisa conjuntamente são mais baixos do que se elas fossem feitas separadamente. Existe também economia de escopo quando há diversos grupos de especialistas trabalhando dentro de um laboratório de pesquisa e estes podem ser usados em outras pesquisas (Henderson; Cockburn, 1996, p. 35). 
dos anos 1990, de novas tecnologias na pesquisa de medicamentos, baseada principalmente na biologia molecular e em novas técnicas da biotecnologia, assim como o uso da informática, possibilitando que empresas menores e altamente especializadas obtivessem sucesso na descoberta de novos medicamentos. Isso levou as grandes empresas a estabelecerem joint ventures com as novas empresas de biotecnologia ou a firmarem alianças comerciais, que licenciaram a fabricação de novos medicamentos ou negociaram seus direitos de distribuição.

As megafusões e aquisições têm impacto direto nas alterações nos rankings das empresas, conforme verificado pelas análises de Turnover e pelo aumento da concentração. A recente aquisição da Bayer acarretou a demissão de oitocentos empregados americanos devido ao fechamento de plantas e aos rearranjos produtivos. ${ }^{17}$ Diversos executivos da indústria reconhecem que nem sempre as megafusões trazem aumento da produtividade e redução dos custos de P\&D. As fusões podem parar o trabalho dos pesquisadores fazendo com que as linhas de pesquisas sejam revisadas e os projetos reavaliados. Assim, por exemplo, a GlaxoSmithKline dividiu a sua equipe de P\&D em grupos menores baseado em áreas de terapia para encorajá-los em níveis de inovação semelhantes aos das menores empresas rivais de biotecnologia.

No Quadro 2, pode-se verificar que quase todas as vinte e três F\&A realizadas no período entre 1989 e 2006 foram do tipo horizontal, com exceção da Johnson \& Johnson com a ALZA Corporation, que se caracterizou por ser do tipo extensão de produtos. As transações das grandes fusões e aquisições são, na sua maioria, financiadas pelos grandes bancos americanos e europeus, que têm interesse em aumentar seus lucros com os empréstimos.

Quadro 2

Principais F\&A entre as maiores empresas do mundo (1989-2006)

\begin{tabular}{|l|l|c|l|c|c|l|}
\hline Ano & $\begin{array}{c}\text { Empresa (1) } \\
\text { (fez a fusão ou } \\
\text { aquisição) }\end{array}$ & $\begin{array}{c}\text { País de } \\
\text { origem } \\
(1)\end{array}$ & Empresa (2) & $\begin{array}{c}\text { País de } \\
\text { origem } \\
(2)\end{array}$ & $\begin{array}{c}\text { Valor } \\
\text { US\$ bil. }\end{array}$ & Nova empresa \\
\hline 2006 & Nycomed A/S & $\begin{array}{c}\text { Dina- } \\
\text { marca }\end{array}$ & Altana Pharma AG & $\begin{array}{c}\text { Alema- } \\
\text { nha }\end{array}$ & 5,8 & Nycomed A/S \\
\hline 2006 & Bayer AG & $\begin{array}{c}\text { Alema- } \\
\text { nha }\end{array}$ & Schering AG & $\begin{array}{c}\text { Alema- } \\
\text { nha }\end{array}$ & 19,0 & Bayer AG \\
\hline 2005 & $\begin{array}{l}\text { Yamanouchi } \\
\text { Pharmaceutical Co. Ltd. }\end{array}$ & $\begin{array}{c}\text { Japão } \\
\text { Sanofi-Synthélabo S.A. }\end{array}$ & $\begin{array}{l}\text { Fujisawa } \\
\text { Pharmaceutical Co. Ltd. }\end{array}$ & $\begin{array}{c}\text { Japão } \\
\text { Aventis-Pharma }\end{array}$ & $\begin{array}{c}\text { Alema- } \\
\text { nha }\end{array}$ & $\begin{array}{l}\text { Astella Pharma } \\
\text { Inc. }\end{array}$ \\
\hline
\end{tabular}

Continua...

(17) Disponível em: <http://www.llave.connmed.com.ar/portalnoticias_vernoticia.php?codigonoticia $\equiv 10372>$. Acesso em: 15 dez. 2007. 
Gerson Rosenberg / Maria da Graça Derengowski Fonseca / Luiz Antonio d' Avila

\begin{tabular}{|c|c|c|c|c|c|c|}
\hline Ano & $\begin{array}{l}\text { Empresa (1) } \\
\text { (fez a fusão ou } \\
\text { aquisição) }\end{array}$ & $\begin{array}{l}\text { País de } \\
\text { origem } \\
\text { (1) }\end{array}$ & Empresa (2) & $\begin{array}{l}\text { País de } \\
\text { origem } \\
\text { (2) }\end{array}$ & $\begin{array}{c}\text { Valor } \\
\text { US\$ bil. }\end{array}$ & Nova empresa \\
\hline 2003 & Pfizer Inc & EUA & Pharmacia Corporation & EUA & 60,0 & Pfizer Inc \\
\hline 2001 & Johnson \& Johnson Co. & EUA & $\begin{array}{l}\text { ALZA Corporation } \\
\text { (Biofarmacêutica) }\end{array}$ & EUA & 10,5 & $\begin{array}{l}\text { Johnson \& } \\
\text { Johnson Co. }\end{array}$ \\
\hline 2000 & Glaxo Wellcome Plc. & $\begin{array}{l}\text { Reino } \\
\text { Unido }\end{array}$ & SmithKline Beecham & $\begin{array}{l}\text { Reino } \\
\text { Unido }\end{array}$ & 70,0 & $\begin{array}{l}\text { GlaxoSmithKlin } \\
\text { e Plc }\end{array}$ \\
\hline 2000 & Pfizer Inc. & EUA & Warner-Lambert Corp. & EUA & 91,0 & Pfizer Inc. \\
\hline 1999 & Monsanto Company & EUA & $\begin{array}{l}\text { Pharmacia \& Upjohn } \\
\text { Inc. }\end{array}$ & EUA & 27,0 & $\begin{array}{l}\text { Pharmacia } \\
\text { Corporation }\end{array}$ \\
\hline 1999 & $\begin{array}{l}\text { Hoechst Marion } \\
\text { Roussel }\end{array}$ & $\begin{array}{c}\text { Alema- } \\
\text { nha }\end{array}$ & Rhône-Poulenc & França & 16,0 & $\begin{array}{l}\text { Aventis-Pharma } \\
\text { (Alemanha) }\end{array}$ \\
\hline 1999 & Astra AB & Suécia & Zeneca Group Plc. & $\begin{array}{l}\text { Reino } \\
\text { Unido }\end{array}$ & 30.5 & $\begin{array}{l}\text { AstraZeneca } \\
\text { Plc.(Inglaterra) }\end{array}$ \\
\hline 1998 & Sanofi S.A. & França & Synthélabo S.A. & França & 9,0 & $\begin{array}{l}\text { Sanofi- } \\
\text { Synthélabo S.A. }\end{array}$ \\
\hline 1997 & $\begin{array}{l}\text { F. Hoffman-la Roche } \\
\text { Ltd. }\end{array}$ & Suíça & Boehringer Mannheim & $\begin{array}{c}\text { Alema- } \\
\text { nha }\end{array}$ & 11,0 & $\begin{array}{l}\text { F. Hoffman-la } \\
\text { Roche }\end{array}$ \\
\hline 1996 & Sandoz Ltd. & Suíça & Ciba-Geigy Ltd. & Suíça & 63,0 & Novartis AG \\
\hline 1995 & Pharmacia AB & Suíça & The Upjohn Company & EUA & 13,0 & $\begin{array}{l}\text { Pharmacia \& } \\
\text { Upjohn } \\
\text { Inc.(EUA) }\end{array}$ \\
\hline 1995 & Hoechst Roussel AG & $\begin{array}{c}\text { Alema- } \\
\text { nha }\end{array}$ & $\begin{array}{l}\text { Marion Merrill Dow } \\
\text { Inc. (Lepetit) }\end{array}$ & EUA & 7,0 & $\begin{array}{l}\text { Hoechst Marion } \\
\text { Roussel } \\
\text { (Alemanha) }\end{array}$ \\
\hline 1995 & Glaxo Plc. & $\begin{array}{l}\text { Reino } \\
\text { Unido }\end{array}$ & $\begin{array}{l}\text { Burroughs Wellcome } \\
\text { Co. }\end{array}$ & $\begin{array}{l}\text { Reino } \\
\text { Unido }\end{array}$ & 14,9 & $\begin{array}{l}\text { GlaxoWellcome } \\
\text { Plc. }\end{array}$ \\
\hline 1994 & $\begin{array}{l}\text { American Home } \\
\text { Products Corp.(Wyeth) }\end{array}$ & EUA & $\begin{array}{l}\text { American Cyanamid } \\
\text { Co. (Lederle) }\end{array}$ & EUA & 10,0 & $\begin{array}{l}\text { American Home } \\
\text { Products } \\
\text { (Wyeth) }\end{array}$ \\
\hline 1994 & Roche Holding Ltd. & Suiça & Syntex Corporation & EUA & 5,3 & $\begin{array}{l}\text { Roche Holding } \\
\text { Ltd. }\end{array}$ \\
\hline 1993 & Kabi Pharmacia Ltd. & Suiça & Farmitalia Carlo Erba & Itália & nd & $\begin{array}{l}\text { Pharmacia AB } \\
\text { (Suíça) }\end{array}$ \\
\hline 1990 & $\begin{array}{l}\text { Pharmacia Aktiebolag } \\
\text { Ltd. }\end{array}$ & Suiça & Kabi Vitrum Ltd. & Suiça & nd & $\begin{array}{l}\text { Kabi Pharmacia } \\
\text { Ltd. (Suiça) }\end{array}$ \\
\hline 1989 & $\begin{array}{l}\text { SmithKline Beckman } \\
\text { Plc. }\end{array}$ & $\begin{array}{l}\text { Reino } \\
\text { Unido }\end{array}$ & $\begin{array}{l}\text { The Beecham Group } \\
\text { Plc }\end{array}$ & $\begin{array}{l}\text { Reino } \\
\text { Unido }\end{array}$ & nd & $\begin{array}{l}\text { SmithKline } \\
\text { Beecham Plc. }\end{array}$ \\
\hline 1989 & Bristol-Myers Inc. & EUA & Squibb Corporation & EUA & nd & $\begin{array}{l}\text { Bristol-Myers } \\
\text { Squibb }\end{array}$ \\
\hline
\end{tabular}

Fonte: Elaboração própria a partir dos Relatórios Anuais das empresas e dos relatórios do Federal Trade Commission dos EUA. Legenda: nd = não disponível.

Segundo o estudo da KPMG Consultoria Ltda. (2001, p. 6), o volume de transações envolvendo capital estrangeiro no Brasil por meio de fusões e aquisições cresceu mais de 44,0 \% ao longo da década de 1990. Das 2.308 operações realizadas no período, 61,0\% envolveram recursos estrangeiros. Os 
Estados Unidos foram o país que mais investiu no Brasil, seguido de França, Portugal e Espanha. Os setores em que mais houve fusões e aquisições foram: alimento, produtos químicos e petroquímicos, metalurgia e siderurgia, financeiro, eletroeletrônico, autopeças, telecomunicações, tecnologia da informação, publicitário e editorial. É importante observar que o setor farmacêutico não aparece, nesta pesquisa, entre os setores principais que tiveram fusões e aquisições, isto porque não houve nenhum processo de privatização envolvendo laboratórios farmacêuticos públicos e também nenhum tipo de apoio governamental ou interesse das multinacionais neste setor, como na década de setenta e oitenta. O Quadro 3 mostra as poucas fusões e aquisições ocorridas no período de 1988 a 2006 no mercado farmacêutico brasileiro.

Quadro 3

Principais fusões e aquisições das empresas brasileiras

\begin{tabular}{|c|c|c|c|}
\hline Período & Empresa (1) & $\begin{array}{l}\text { Empresa (2) } \\
\text { (Fusão ou Aquisição) }\end{array}$ & Nova Empresa \\
\hline \multirow{6}{*}{$\begin{array}{l}1988- \\
1999\end{array}$} & Laboratório Honor Terápico & Laboratório Cimed & $\begin{array}{l}\text { Laboratório Windson (mudou de } \\
\text { nome em } 2005 \text { para Cimed) }\end{array}$ \\
\hline & Laboratório Newlab & Laboratório Dorsay & DM Farmacêutica \\
\hline & Laboratório ISA & $\begin{array}{l}\text { Laboratório Majer Meyer e } \\
\text { Laboratório INAF }\end{array}$ & Eurofarma \\
\hline & $\begin{array}{l}\text { União Química } \\
\text { Farmacêutica Nacional S.A. }\end{array}$ & $\begin{array}{l}\text { Biolab Sanus Farmacêutica Ltda } \\
\text { e Laboratório Naturin }\end{array}$ & Grupo Castro Marques \\
\hline & Laboratório EMS & $\begin{array}{l}\text { Laboratório Legrand, } \\
\text { Laboratório Nature's Plus e } \\
\text { Laboratório Novaquímica }\end{array}$ & EMS S.A. \\
\hline & Hexal AG & $\begin{array}{l}\text { Química Intercontinental } \\
\text { Farmacêutica (QIF) }\end{array}$ & Hexal do Brasil Ltda \\
\hline \multirow{6}{*}{$\begin{array}{l}1999 \\
2006\end{array}$} & EMS S.A. & Laboratório Sigma Pharma & EMS- Sigma Pharma \\
\hline & Solvay Pharmaceuticals Inc & Laboratórios Sintofarma S.A. & Solvay do Brasil Ltda \\
\hline & $\begin{array}{l}\text { Novo Nordisk Holding do } \\
\text { Brasil Ltda }\end{array}$ & Biobrás S.A. & $\begin{array}{l}\text { Novo Nordisk Holding do Brasil } \\
\text { Ltda }\end{array}$ \\
\hline & Merck Sharp \& Dohme Ltda & $\begin{array}{l}\text { Prodome Química e } \\
\text { Farmacêutica Ltda (joint venture } \\
\text { entre a Merck Sharp \& Dohme } \\
\text { Ltda e a Aché Laboratórios } \\
\text { Farmacêuticos S/A) }\end{array}$ & Merck Sharp \& Dohme Ltda \\
\hline & $\begin{array}{l}\text { Aché Laboratórios } \\
\text { Farmacêuticos S/A }\end{array}$ & ASTA Medica Ltda & $\begin{array}{l}\text { Aché Laboratórios } \\
\text { Farmacêuticos S/A }\end{array}$ \\
\hline & $\begin{array}{l}\text { Aché Laboratórios } \\
\text { Farmacêuticos S/A }\end{array}$ & Biosintética Farmacêutica Ltda & $\begin{array}{l}\text { Aché Laboratórios } \\
\text { Farmacêuticos S/A }\end{array}$ \\
\hline
\end{tabular}

Fonte: Elaboração própria a partir dos Pareceres Técnicos da Secretaria de Acompanhamento Econômico (SEAE) do Ministério da Fazenda (Disponível em: < http://www.fazenda.gov.br/seae/littera/exec/controle. asp?boPesq=true \&acao=pesquisa\&dscnum processo=\&csPesq=and\&nom interessado=ach $\%$ E9\&idTipo=1\&id SetorFilhoAux=1401\&idSetorPai=14\&idSetorFilho=1401\&ca=\&submit=Pesquisar>. Acesso em: 12 dez. 2007) e Magalhães et al. (2003). 
Nas aquisições apontadas no Quadro 3, o que chama mais a atenção foi a compra da Biobrás pela Novo Nordisk em 2002 por $\mathrm{R} \$ 75,4$ milhões, envolvendo a aquisição de $76 \%$ das ações ordinárias e mais $20 \%$ das ações preferenciais - $3 \%$ pertencentes à Biopart Ltda e 17\% ao BNDES (Callegari, 2003). A Biobrás era uma empresa de capital nacional e a única que produzia insulina humana a partir de matéria-prima animal. A compra da Biobrás pode significar a perda de uma das poucas empresas nacionais com experiência no desenvolvimento tecnológico de fármacos.

A mais recente aquisição foi realizada em maio de 2007 entre a empresa indiana Zydus Cadila, atuante em 50 países, e a nacional Nikkho do Brasil por US\$ 26 milhões. ${ }^{18}$ A Nikkho é uma empresa pequena com fábrica no Rio de Janeiro e possui 13 medicamentos de marca em 22 apresentações. Com a aquisição, a Zydus se posiciona estrategicamente no mercado de genéricos no Brasil, o que pode ser uma ameaça aos produtores nacionais neste segmento do mercado.

Com o intuito de propiciar condições para que as empresas farmacêuticas brasileiras possam ser mais competitivas, foi lançado, em 2004, pelo Banco Nacional de Desenvolvimento Econômico e Social (BNDES), o Programa de Apoio ao Desenvolvimento da Cadeia Produtiva Farmacêutica - Profarma ${ }^{19}$ com o objetivo de apoiar a incorporação, aquisição ou fusão que resultem na criação de empresas de controle nacional de maior porte e/ou mais verticalizadas.

\section{Mobilidade das empresas: análise da situação mundial e no Brasil através do turnover}

A análise turnover, desenvolvida por Joskow (1960), possibilita avaliar a mobilidade das empresas do setor farmacêutico entre dois períodos, ou seja, verificar o grau das mudanças ocorridas nas posições das empresas num determinado ranking. Com o intuito de investigar o impacto da introdução dos medicamentos genéricos no mercado farmacêutico foram analisados dois períodos: um antes da introdução dos genéricos entre 1997 e 2000 e outro compreendido entre 2000 e 2005 . Foram estudadas as cem maiores empresas farmacêuticas em 1997 e, para isto, foram reunidas em 11 grupos de 10 empresas cada, em que os dois primeiros contam com apenas cinco empresas, já que englobam as maiores do setor.

(18) Disponível em: <http://www.valoronline.com.br/valoreconomico.html>. Acesso em: 2 ago. 2007.

(19) Disponível em: <http://www.bndes.gov.br/programas/industriais/profarma.asp\#fortalecimento $>$. Acesso em: 15 dez. 2007. 
Quadro 4

Análise comparativa do turnover entre as 100 maiores empresas farmacêuticas no Brasil entre 1997/2000 e 2000/2005

\begin{tabular}{|c|c|c|c|c|c|c|c|c|c|c|c|c|c|c|c|}
\hline \multirow{2}{*}{ Grupos } & \multicolumn{2}{|c|}{ Ascenderam } & \multicolumn{2}{|c|}{ Desceram } & \multicolumn{2}{|c|}{$\begin{array}{l}\text { Saíram da } \\
\text { Indústria }\end{array}$} & \multicolumn{2}{|c|}{$\operatorname{Ingressaram}(*)$} & \multicolumn{2}{|c|}{$\begin{array}{c}\text { Permaneceram } \\
(\mathrm{NPi})\end{array}$} & \multicolumn{2}{|c|}{$\begin{array}{c}\text { Saíram do } \\
\text { Grupo }\end{array}$} & \multirow[t]{2}{*}{$\begin{array}{c}\mathrm{NE} \\
(\mathrm{NTi})\end{array}$} & \multicolumn{2}{|c|}{$\begin{array}{c}\text { Turnover } \\
\mathrm{Ti}(\%)\end{array}$} \\
\hline & $\begin{array}{c}97 / \\
00\end{array}$ & $\begin{array}{c}00 / \\
05\end{array}$ & $\begin{array}{c}97 / \\
00\end{array}$ & $\begin{array}{l}00 / \\
05\end{array}$ & $\begin{array}{c}97 / \\
00\end{array}$ & $\begin{array}{l}00 / \\
05\end{array}$ & $\begin{array}{c}97 / \\
00\end{array}$ & $\begin{array}{c}00 / \\
05\end{array}$ & $\begin{array}{c}97 / \\
00\end{array}$ & $\begin{array}{l}00 / \\
05\end{array}$ & $\begin{array}{c}97 / \\
00\end{array}$ & $\begin{array}{l}00 / \\
05\end{array}$ & & $\begin{array}{c}97 / \\
00\end{array}$ & $\begin{array}{c}00 / \\
05\end{array}$ \\
\hline$A(1-5)$ & 0 & 0 & 1 & 1 & 0 & 0 & 0 & 0 & 4 & 4 & 0 & 0 & 5 & 20,0 & 20,0 \\
\hline B (6-10) & 0 & 0 & 2 & 4 & 0 & 0 & 0 & 0 & 3 & 1 & 0 & 0 & 5 & 40,0 & 80,0 \\
\hline $\mathrm{C}(11-20)$ & 4 & 4 & 1 & 3 & 2 & 0 & 0 & 0 & 3 & 3 & 0 & 0 & 10 & 70,0 & 70,0 \\
\hline $\mathrm{D}(21-30)$ & 3 & 4 & 1 & 1 & 1 & 1 & 0 & 0 & 5 & 4 & 0 & 0 & 10 & 50,0 & 60,0 \\
\hline E (31-40) & 6 & 3 & 0 & 2 & 1 & 0 & 0 & 0 & 3 & 5 & 0 & 0 & 10 & 70,0 & 50,0 \\
\hline$F(41-50)$ & 5 & 3 & 0 & 3 & 1 & 1 & 0 & 0 & 4 & 3 & 0 & 0 & 10 & 60,0 & 70,0 \\
\hline $\mathrm{G}(51-60)$ & 6 & 1 & 1 & 6 & 1 & 0 & 2 & 2 & 2 & 3 & 0 & 1 & 10 & 80,0 & 70,0 \\
\hline $\mathrm{H}(61-70)$ & 6 & 2 & 0 & 6 & 1 & 0 & 1 & 1 & 3 & 2 & 0 & 0 & 10 & 70,0 & 80,0 \\
\hline I (71-80) & 7 & 3 & 0 & 7 & 0 & 0 & 5 & 5 & 3 & 0 & 0 & 2 & 10 & 70,0 & 100,0 \\
\hline $\mathrm{J}(81-90)$ & 4 & 4 & 3 & 4 & 1 & 0 & 6 & 3 & 2 & 2 & 1 & 2 & 10 & 80,0 & 80,0 \\
\hline $\mathrm{L}(91-100)$ & 4 & 1 & 4 & 9 & 0 & 0 & 6 & 6 & 2 & 0 & 4 & 9 & 10 & 80,0 & 100,0 \\
\hline Total/Média & 45 & 25 & 13 & 46 & 8 & 2 & 20 & 17 & 34 & 27 & 5 & 14 & 100 & 62,7 & 70,9 \\
\hline
\end{tabular}

Legenda: $(*)$ quantidades de empresas que ingressaram nos grupos originais.

Fonte: Elaboração própria segundo a metodologia de Joskow. 
Houve a preocupação de se estabelecer um tamanho não muito grande dos grupos com a finalidade de minimizar impactos indesejáveis de uma determinada empresa no resultado de mobilidade do grupo e de alcançar uma determinada frequência de agrupamento. Desta forma, os dois primeiros grupos foram formados por cinco empresas, ou seja, o grupo A foi formado pelas cinco maiores e o conjunto $\mathrm{B}$ pelas empresas que ocupavam da $6^{\mathrm{a}}$ à $10^{\mathrm{a}}$ posição. Os demais grupos são compostos de dez empresas e assim sucessivamente.

O Quadro 4 apresenta o resumo das mudanças ocorridas nos dois períodos analisados, em que o Índice de Turnover na última coluna, é medido da seguinte forma (Amin; Aguiar, 2005, p. 47):

Turnover $_{i}-T_{i}(\%)=\left(\left(\mathrm{NT}_{\mathrm{i}}-\mathrm{NP}_{\mathrm{i}}\right) / \mathrm{NP}_{\mathrm{i}}\right) * 100$

Em que:

$\operatorname{Turnover}_{i}(\%)=$ índice de turnover $(\mathrm{em} \%)$;

$N T_{i}=$ número total de empresas no grupo i;

$\boldsymbol{N P}_{\boldsymbol{i}}=$ número de empresas que permaneceram no grupo i.

As seguintes considerações podem ser elaboradas a partir do Quadro 4: (i) baixo índice do turnover $\left(\mathrm{T}_{\mathrm{i}}\right)$ entre as cinco primeiras colocadas para o dois períodos analisados, indicando que as empresas líderes não tiveram suas posições afetadas com a introdução dos genéricos; (ii) no período entre 1997 e 2000 houve um número maior de ascensão de empresas dentro dos grupos, o que pode ser atribuído principalmente à maior quantidade de fusões e aquisições ocorridas entre as grandes empresas do setor; (iii) no período entre 2000 e 2005, observa-se um número maior de empresas que desceram de grupo e um maior índice do $\mathrm{T}_{\mathrm{i}}$, o que pode ser caracterizado pela entrada dos genéricos; (iv) verifica-se um número considerável de empresas que saíram entre 1997 e 2000 devido a maior quantidade de empresas adquiridas neste período.

\section{Por que fabricar medicamentos genéricos: antecedentes (EUA e Brasil)}

Para se compreender como os medicamentos genéricos surgiram no Brasil e no mundo, cabe destacar o seu surgimento nos Estados Unidos da América, que é o maior mercado farmacêutico mundial e o primeiro país a adotar uma legislação específica sobre medicamentos genéricos.

O Food and Drug Administration (FDA) foi criado em 1927 devido à necessidade de se ter uma agência regulamentadora nacional para o setor farmacêutico, pois, até esta data, cada um dos Estados da Federação gozava de elevada autonomia para fazer a regulamentação dos seus medicamentos e alimentos. Todavia, a indústria de medicamentos genéricos iniciou-se nos EUA, em 1962, quando o governo decidiu aprovar a Lei Kefauver-Harris, que exigiu que 
as empresas comprovassem a segurança e a eficácia dos medicamentos produzidos. A discussão sobre os medicamentos genéricos é anterior à referida Lei, uma vez que, no início da década de cinquenta, nos Estados Unidos, surgiram inúmeros medicamentos similares que trouxeram duas consequências: (i) os farmacêuticos tiveram que dispensar ${ }^{20}$ novos produtos, fazendo com que precisassem de um estoque maior de medicamentos e (ii) o aumento das imitações de produtos frequentemente de qualidade inferior. Em 1953, reuniram-se os fabricantes para criar o Nacional Pharmaceutical Council com o intuito específico de combater a substituição dos medicamentos. As leis antissubstituição americanas surgidas nesta época requereram dos farmacêuticos dispensar medicamentos prescritos pelos médicos, indicando, assim, uma marca ou um medicamento genérico produzido por um fabricante específico. As leis antissubstituição resolveram a questão da distribuição de medicamentos de qualidade inferior, mas, por outro lado, limitaram a probabilidade dos medicamentos genéricos serem fabricados, preservando os produtos de marca no mercado americano após os dezessete anos da validade da patente (Ascione et al., 2001).

Em 1965, iniciou-se uma investigação pelo Congresso Americano sobre os custos dos medicamentos para o governo e para o público após a aprovação da emenda Medicaid and Medicare pela Lei Social Security. O Senador Russel Long, em 1967, introduziu a legislação obrigando o uso de produtos genéricos para o apoio a programas de saúde e bem-estar. A revogação das leis antissubstituição ganhou apoio em 1971 quando a American Pharmacists Association (APhA) publicou um artigo sobre uma política compreensiva e fundamentos científicos para a seleção de produtos substitutos pelos farmacêuticos. Porém, a American Medical Association se opôs à modificação das leis antissubstituição, temendo perda de controle por parte dos médicos sobre os tratamentos terapêuticos ministrados aos pacientes. A APhA contra-argumentou que os farmacêuticos eram considerados os profissionais de saúde mais aptos a dispensar o melhor medicamento para o paciente e que a ampliação da regra levaria a uma maior cooperação com os médicos.

Nesta ocasião, havia a preocupação relacionada com os medicamentos que aparentavam serem iguais, contendo as mesmas substâncias químicas, mas que, na verdade, não eram totalmente bioequivalentes. ${ }^{21}$ Adicionalmente, existia a dúvida se os farmacêuticos eram qualificados para diferenciar os produtos baseados em

\footnotetext{
(20) Dispensação - ato de fornecimento ao consumidor de drogas, medicamentos, insumos farmacêuticos e correlatos, a título remunerado ou não. Disponível em: <http://www.anvisa.gov.br/medicamentos/ conceito.htm\#4> . Acesso em: 8 jan. 2007.

(21) Bioequivalência é o estudo comparativo entre dois ou mais medicamentos administrados em uma mesma via extravascular. Avalia os parâmetros relacionados à absorção do fármaco a partir da forma farmacêutica administrada, contendo a mesma dosagem e o mesmo desenho experimental. Disponível em: <http://www.anvisa.gov.br/hotsite/genericos/profissionais/conceitos.htm\#3>. Acesso em: 8 fev. 2007.
} 
sua biodisponibilidade. ${ }^{22}$ O National Research Council do National Academy of Sciences foi convidado, em 1975, para colaborar na emenda das leis para substituição de medicamentos, conferindo ao farmacêutico maior autoridade para a seleção dos mesmos.

Em 1980, nos EUA, quarenta e cinco Estados da Federação permitiram medicamentos substitutos ou a seleção de produtos (Ascione et al., 2001, p. 4). Apesar disso, somente em 1984 foram criadas as condições necessárias e ideais para o surgimento da indústria de medicamentos genéricos nos EUA. As normas foram estabelecidas pelo Drug Price Competition and Patent Restoration Act, que determinou mecanismos mais simples de registro para versões genéricas de todos os medicamentos aprovados após 1962, desde que apresentassem informações sobre sua bioequivalência e processo produtivo, além de outras exigências, comprovando ser igual ao produto original (biodisponibilidade).

Essas mudanças diminuíram o período entre a expiração da patente e o lançamento do genérico de mais de três anos para menos de três meses. Após o Drug Price Competition and Patent Restoration Act o mercado de genéricos nos EUA cresceu muito. Considerando somente os medicamentos de uso oral, como cápsulas, comprimidos e drágeas, o aumento na participação das vendas passou de $18,4 \%$ para $42,6 \%$ entre 1984 e $1996 .^{23}$

No Brasil, desde 1976, as indústrias farmacêuticas foram autorizadas a registrar produtos similares ao medicamento de referência. Em 1983, tornou-se obrigatório utilizar o nome genérico segundo a Denominação Comum Brasileira (DCB) da substância ativa nas embalagens de medicamentos, além da marca comercial. Em 1991, começou a tramitar na Câmara dos Deputados, em Brasília, o Projeto de Lei n. 2002, que visava abolir as marcas comerciais das embalagens dos medicamentos, ou seja, foi a primeira tentativa para a implementação dos medicamentos genéricos no país.

Este projeto deu origem ao Decreto 793/93 de 5 de abril de 1993, que determinava o uso da DCB do fármaco nas embalagens dos medicamentos em tamanho três vezes maior que o nome comercial. Entretanto, as diretrizes deste decreto não foram implantadas integralmente devido a aspectos técnicos.

Em 1999, a Lei 9.787 de 10 de fevereiro institui o medicamento genérico no país de acordo com as normas internacionais adotadas por países da Comunidade Européia, EUA e Canadá, além da Organização Mundial de Saúde (OMS). A Lei 9.787/99 foi regulamentada pela Resolução 391 de 9 de agosto de

(22) Biodisponibilidade está relacionada à eficácia clínica do medicamento. Traduz-se na velocidade e quantidade do princípio ativo ou fármaco, que alcança a circulação geral. Disponível em: <http://www.anvisa.gov.br/hotsite/genericos/profissionais/conceitos.htm\#3>. Acesso em: 8 fev. 2007.

(23) Disponível em: <http://www.progenericos.org.br/historia.shtml>. Acesso em: 7 fev. 2007. 
1999, que apresentou todos os critérios sobre produção, ensaios de bioequivalência, ensaios de biodisponibilidade, registro, prescrição e dispensação de medicamentos genéricos. Em 3 de fevereiro de 2000, foram registrados os seis primeiros medicamentos genéricos do país: Ampicilina sódica (antibiótico), Cefalexina (antibiótico), Cloridrato de Ranitidina (antiulceroso), Cetononazol (antimicótico), Furosemida (diurético) e Sulfato de Salbutamol (broncodilatador).

Em dezembro de 2000, já haviam sido registrados cento e oitenta e nove medicamentos genéricos de quinze laboratórios. Os fármacos genéricos comercializados em farmácias representavam as seguintes classes terapêuticas: antibióticos, penicilínicos, anti-hipertensivos, anti-infecciosos, antimicóticos, antiulcerosos, expectorantes, analgésicos, entre outros. Atualmente, várias doenças graves já podem ser tratadas com medicamentos genéricos como Diabetes, Aids, Glaucoma, Hipertensão, Câncer de Mama e Mal de Parkinson. Em janeiro de 2001, foi publicada a Resolução 10 em substituição à Resolução 391, de 09 de agosto de 1999, com o objetivo de dar maior agilidade ao processo de registro dos medicamentos genéricos e melhorar o fluxo das análises. A norma agregou informações, revisou pontos da resolução original e preencheu lacunas, como a regularização do registro de genéricos importados.

A adoção da Política Nacional de Medicamentos Genéricos pelo Governo Federal está inserida na política assistencial e do uso racional de medicamentos no Brasil, envolvendo a produção, a garantia da qualidade, a formulação, a prescrição, a dispensação e o uso dos medicamentos genéricos. Para alcançar o seu principal objetivo que é o acesso da população aos medicamentos, é fundamental a participação ativa e consciente dos profissionais responsáveis pela prescrição e dispensa dos medicamentos, tais como: médicos, dentistas e farmacêuticos. Um dos principais requisitos para a implementação da política dos genéricos é a prescrição através da Denominação Comum Brasileira (DCB) ou pela Denominação Comum Internacional. A prescrição com a denominação genérica do medicamento é somente obrigatória no serviço público do Sistema Único de Saúde (SUS). Nos demais casos, fica a critério do médico prescrever ou não medicamentos pelo nome genérico. O Ministério da Saúde fez, em 2002, uma campanha de divulgação dos medicamentos genéricos com o objetivo de educar os consumidores a reconhecê-los nas farmácias, o que resultou no aumento de sua procura.

\subsection{Concentração da indústria farmacêutica de medicamentos genéricos no Brasil}

O mercado brasileiro de genéricos no final de 2005 era composto por 63 firmas que fizeram pedidos de registros para comercialização de medicamentos genéricos na Anvisa, abrangendo 88 classes terapêuticas e 93,0 \% da necessidade da prescrição médica. 
Quadro 5

Market-share das empresas no mercado de medicamentos genéricos no Brasil

\begin{tabular}{|c|c|c|c|c|c|c|c|c|c|c|c|}
\hline \multicolumn{2}{|c|}{ Ano 2000} & \multicolumn{2}{|c|}{ Ano 2001} & \multicolumn{2}{|c|}{ Ano 2002} & \multicolumn{2}{|c|}{ Ano 2003} & \multicolumn{2}{|c|}{ Ano 2004} & \multicolumn{2}{|c|}{ Ano 2005} \\
\hline $\begin{array}{c}\text { Ranking } \\
\text { decrescente } \\
\text { das empresas }\end{array}$ & $\begin{array}{c}\text { Venda } \\
\%\end{array}$ & $\begin{array}{c}\text { Ranking } \\
\text { decrescente } \\
\text { das empresas }\end{array}$ & $\begin{array}{c}\text { Venda } \\
\%\end{array}$ & $\begin{array}{c}\text { Ranking } \\
\text { decrescente } \\
\text { das empresas }\end{array}$ & $\begin{array}{c}\text { Venda } \\
\%\end{array}$ & $\begin{array}{c}\text { Ranking } \\
\text { decrescente } \\
\text { das empresas }\end{array}$ & $\begin{array}{c}\text { Venda } \\
\%\end{array}$ & $\begin{array}{c}\text { Ranking } \\
\text { decrescente } \\
\text { das empresas }\end{array}$ & $\begin{array}{c}\text { Venda } \\
\%\end{array}$ & $\begin{array}{c}\text { Ranking } \\
\text { decrescente } \\
\text { das empresas }\end{array}$ & $\begin{array}{c}\text { Venda } \\
\%\end{array}$ \\
\hline EMS & 34,03 & Medley & 31,23 & Medley & 27,34 & Medley & 25,91 & Medley & 27,61 & Medley & 27,96 \\
\hline Medley & 31,46 & EMS & 26,32 & EMS & 20,14 & EMS & 20,31 & EMS & 21,16 & EMS & 25,97 \\
\hline Biosintetica & 28,42 & Biosintetica & 20,31 & Biosintetica & 17,47 & Biosintetica & 14,06 & Biosintetica & 12,30 & $\begin{array}{l}\text { Aché/ } \\
\text { Biosintetica }\end{array}$ & 12,21 \\
\hline Eurofarma & 3,75 & Eurofarma & 9,45 & Eurofarma & 10,92 & Eurofarma & 10,42 & Eurofarma & 10,10 & Eurofarma & 8,92 \\
\hline Teuto & 2,12 & Ranbaxy & 8,37 & Ranbaxy & 10,49 & Ranbaxy & 8,93 & Ranbaxy & 7,32 & Ranbaxy & 5,12 \\
\hline Neo Quimica & 0,08 & Merck & 1,37 & Novartis & 3,88 & Apotex & 4,73 & Novartis & 4,89 & Novartis & 4,35 \\
\hline Ducto & 0,04 & Teuto & 1,21 & Merck & 2,57 & Novartis & 4,60 & Merck & 3,42 & Merck & 2,92 \\
\hline Ranbaxy & 0,03 & Novartis & 0,63 & $\begin{array}{l}\text { Hexal do } \\
\text { Brasil }\end{array}$ & 1,66 & Merck & 3,32 & Apotex & 2,95 & $\begin{array}{l}\text { Hexal do } \\
\text { Brasil }\end{array}$ & 2,14 \\
\hline
\end{tabular}

Fonte: Elaboração própria a partir dos dados fornecidos pelo IMS Health do Brasil em 2006. 
O Quadro 5 mostra o ranking das oito maiores empresas de genéricos no período de 2000 a 2005 com o respectivo percentual de vendas, sendo as quatro primeiras colocadas brasileiras. A Medley é a que possuía maior poder de mercado ao longo de 2000 a 2005, pois o seu faturamento estava bastante acima dos demais concorrentes, atingindo, neste período, em média, 28,6\% do mercado de medicamentos genéricos, enquanto a segunda colocada, EMS Sigma Pharma, tinha, em média, 24,7 \%. Em seguida vêm as empresas Aché/Biosintética, Eurofarma e Ranbaxy, cujas posições permaneceram inalteradas ao longo deste período. Cabe ressaltar que, das oito maiores empresas no referido período, somente a canadense Apotex se dedicava exclusivamente à comercialização de medicamentos genéricos no Brasil, enquanto as demais empresas comercializavam também medicamentos de marca.

A partir da participação de cada empresa no mercado de medicamentos genéricos, pode-se calcular a concentração através da Razão de Concentração (CR) e do índice de Hirschman-Herfindahl $\left(\mathrm{HH}_{\mathrm{i}}\right)$, conforme mostra a Figura 5. Os índices de concentração CR(4) e CR (8) do segmento de genéricos (Figura 4) é bem maior que o do setor farmacêutico brasileiro como um todo (Figura 3) devido à existência, ainda, de poucas empresas atuando neste tipo de mercado.

Figura 4

Índice de concentração industrial para o mercado de genéricos no Brasil

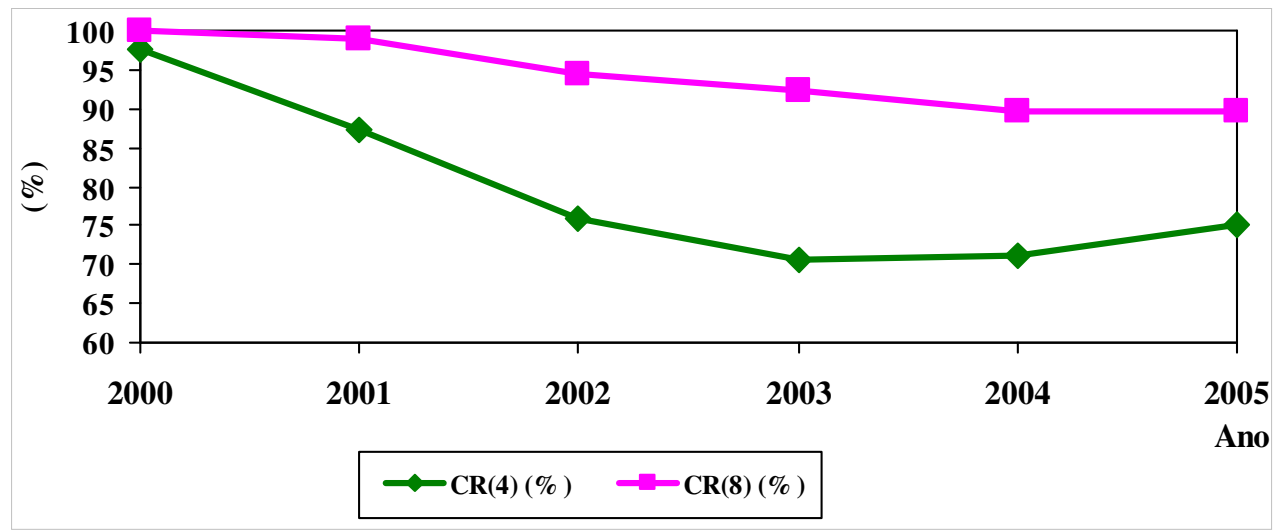

Fonte: Elaboração própria a partir das informações obtidas no IMS do Brasil (2006).

A partir da Figura 4, algumas conclusões referentes à concentração são apontadas no período entre 2000 e 2005: (i) o nível de concentração do mercado CR (4) e CR(8) diminuiu no intervalo de 2000 a 2003, pois o número de novas empresas que solicitaram registros de genéricos na Anvisa aumentou de $14 \mathrm{em}$ 2001 para 46 em 2003; (ii) apesar do aumento do número de novos entrantes entre 2004 e 2005, 55 para 63, respectivamente, o nível de concentração CR (4) e CR(8) aumentou consideravelmente neste período, principalmente pela maior 
participação da EMS Sigma Pharma, como visto no Quadro 5; (iii) a fatia do mercado que as quatro maiores empresas dividem permaneceu praticamente inalterada no período estudado; (iv) como a razão de concentração é próxima de um, pode-se afirmar que se trata de um setor industrial de pouca concorrência; (v) as oito maiores empresas $\mathrm{CR}(8)$ possuem um alto poder de mercado em relação às demais empresas que atuam no mercado de medicamentos de genéricos e (vi) no período entre 2000 e 2005 o CR(1) médio das empresas foi de 29,0\%, o que, segundo a legislação brasileira, caracteriza um mercado bastante concentrado.

$\mathrm{O}$ índice de concentração calculado por meio do $\mathrm{HH}_{\mathrm{i}}$ na Figura 5 mostrou um valor bastante acima de $1800\left(\mathrm{HH}_{\mathrm{i}}>1800\right)$ para os anos de 2000 e 2001, ficando próximo deste valor para o período entre 2002 e 2005 , o que leva a considerar o segmento de medicamentos genéricos como de alta concentração. $\mathrm{O}$ índice $\mathrm{HH}_{\mathrm{i}}$ reduziu bastante no período de 2002 a 2003, mostrando uma correlação com o CR e enfatizando a redução do poder de monopólio das empresas. $\mathrm{O}$ número de equivalentes $\left(\mathrm{v}_{\mathrm{H}}\right)$ aumentou com a redução do $\mathrm{HH}_{\mathrm{i}}$, o que enfatiza um processo de desconcentração no período de 2000 a 2003.

Figura 5

Índice de HHi e número de equivalente para o mercado de genéricos

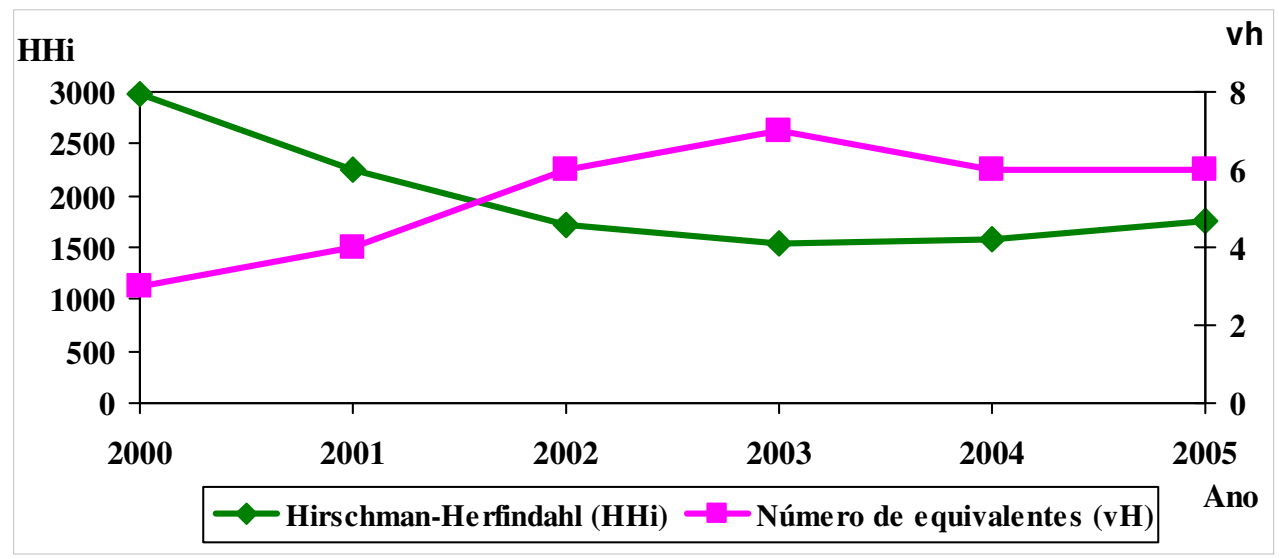

Fonte: Elaboração própria a partir das informações obtidas no IMS do Brasil (2006).

\subsection{Análise de Turnover para o segmento de genéricos}

Análise semelhante foi feita para as dezenove primeiras empresas que somente comercializaram genéricos no Brasil a partir de 2000, com o objetivo de verificar a mobilidade das mesmas, conforme mostra o Quadro 6. 
Análise comparativa da concentração industrial e de turnover da indústria farmacêutica no Brasil...

Quadro 6

Análise comparativa do turnover entre as 19 empresas de genéricos no Brasil entre 2001/2005

\begin{tabular}{|l|c|c|c|c|c|c|c|c|}
\hline Grupos & $\begin{array}{c}\text { Ascen- } \\
\text { deram }\end{array}$ & $\begin{array}{c}\text { Desce- } \\
\text { ram }\end{array}$ & $\begin{array}{c}\text { Saíram } \\
\text { da } \\
\text { indústria }\end{array}$ & $\begin{array}{c}\text { Ingres- } \\
\text { saram } \\
(*)\end{array}$ & $\begin{array}{c}\text { Perma- } \\
\text { neceram } \\
\left(\mathrm{NP}_{\mathrm{i}}\right)\end{array}$ & $\begin{array}{c}\text { Saíram } \\
\text { do grupo }\end{array}$ & $\begin{array}{c}\mathrm{NE} \\
\left(\mathrm{NT}_{\mathrm{i}}\right)\end{array}$ & $\begin{array}{c}\text { Turnover } \\
\mathrm{T}_{\mathrm{i}}(\%)\end{array}$ \\
\hline $\mathrm{A}(1-5)$ & 0 & 0 & 1 & 0 & 4 & 0 & 5 & 20,0 \\
\hline B (6-10) & 0 & 3 & 0 & 0 & 2 & 0 & 5 & 60,0 \\
\hline C (11-19) & 3 & 3 & 0 & 3 & 3 & 3 & 9 & 66,7 \\
\hline $\begin{array}{l}\text { Total/ } \\
\text { Média }\end{array}$ & 3 & 6 & 1 & 3 & 9 & 3 & 19 & 48,9 \\
\hline
\end{tabular}

Legenda: (*) quantidades de empresas que ingressaram nos grupos originais.

Fonte: Elaboração própria segundo a metodologia de Joskow.

Os seguintes comentários podem ser feitos com base no Quadro 6: (i) o índice $\mathrm{T}_{\mathrm{i}}$ igual a 20,0\% para as cinco primeiras empresas indica que as mesmas lideram o mercado, o que lhes facilita o exercício de um maior poder de mercado; (ii) a partir da $6^{\mathrm{a}}$ posição, o maior índice de turnover $\left(\mathrm{T}_{\mathrm{i}}\right.$ maior que $60 \%$ ) pode ser atribuído à perda de posições das empresas que estavam nos grupos B e C, ocasionada por novas empresas entrantes no segmento de genéricos a partir, principalmente, de 2004 e (iii) a maioria das empresas permaneceu nos grupos originais e poucas saíram, mostrando fortalecimento das mesmas.

Os Quadros 4 e 6 mostram uma semelhança entre os índices de turnover para o Grupo A de empresas atuando no setor farmacêutico e no segmento de genéricos, mostrando que elas são pouco afetadas por novos entrantes. Entretanto, o turnover médio para o segmento de genéricos é bem menor que o do setor farmacêutico devido à maior concentração do primeiro.

\section{Conclusões}

Este estudo permite concluir que, em relação às mudanças estruturais, o mercado farmacêutico brasileiro tem mantido a forma estrutural de oligopólio para ambos os segmentos de marca e genéricos, e que este último, de acordo com os dados analisados no artigo, tem se mostrado mais concentrado nos mercados relevantes. Os valores calculados para as taxas de concentração das quatro, oito e dez maiores empresas farmacêuticas que atuam no Brasil permitem identificar que a estrutura do mercado pouco se modificou no período analisado, entre 1999 e 2005, cuja tendência foi impulsionada pelo processo de fusões e aquisições ocorridas nos últimos anos da década de 1990, principalmente das grandes empresas multinacionais. Há evidências de que as mudanças estruturais que se verificaram em função do aumento do processo de fusões e aquisições entre empresas farmacêuticas internacionais desde meados da década de 1990 pouco tem afetado o mercado brasileiro. 
O artigo destaca algumas dimensões das mudanças estruturais na indústria farmacêutica ocasionadas pela entrada de fabricantes nacionais no mercado de genéricos. Esta entrada pode estar apresentando efeitos benéficos não só no que se refere à competição quanto à questão do bem-estar do consumidor. Primeiramente, no segmento de genéricos, a análise do turnover indica fortalecimento da indústria nacional. Além disso, a introdução dos medicamentos genéricos possibilita o acesso da população a medicamentos mais baratos.

No entanto, apesar da entrada de novas empresas, o segmento de genéricos não tem evidenciado desconcentração significativa, - pelo menos até 2005. Isso porque as empresas farmacêuticas talvez ainda não tenham percebido as oportunidades competitivas associadas à expansão deste mercado. O mercado de genéricos representa uma grande oportunidade para empresas farmacêuticas brasileiras de pequeno porte cujo conjunto de estratégias para concorrer com as empresas multinacionais é limitado. Fora do potencial de mercado aberto pelos produtos genéricos a alternativa seria a fusão entre empresas menores com o objetivo de aumentar o seu pipeline de produtos. No entanto, observa-se que o processo de fusões e aquisições entre empresas nacionais no Brasil é ainda é pouco significativo e, consequientemente, a existência do risco das empresas nacionais de medicamentos de genéricos serem adquiridas por grandes grupos multinacionais.

Por último, é importante ressaltar que novos estudos, abrangendo um período de tempo maior, seriam necessários para que se pudesse avaliar, de forma mais detalhada, os efeitos da entrada das empresas de medicamentos genéricos no setor farmacêutico no Brasil e seus impactos sobre o comportamento do consumidor brasileiro. Este artigo preocupou-se, essencialmente, em caracterizar a estrutura de mercado do segmento de genéricos. No entanto, os novos estudos deveriam detalhar a competição e a concentração dentro dos segmentos de mercado, e entre as classes terapêuticas.

\section{Referências bibliográficas}

AMIN, M. C.; AGUIAR D. R. D. Concentração industrial, fusões e turnover no setor supermercadista brasileiro. Gestão \& Produção, São Paulo, v. 13, n. 1, p. 45-56, jan./abr. 2006.

ASCIONE, F. J.; KIRKING, D. M.; GAITHER C. A.; WELAGE, L. S. Historical overview of generic medication policy. Journal of The American Pharmaceutical Association, Washington, v. 41, n. 4, p. 567-577, Jul./Aug. 2001.

BAIN, J. S. Industrial organization. 2. ed. New York: John Wiley \& Sons, 1968. 1987.

; QUALLS P. D. Industrial organization: a treatise. London: Jai Press Inc., 
CALLEGARI, L. A. Medicamentos genéricos: estrutura, mercado e perfis de empresas. Panorama Setorial da Gazeta Mercantil, São Paulo, v. 1, p. 1-137, jul. 2003.

COHEN J.; GANGI W.; LINEEN J.; MANARD A. Strategic alternatives In: The Pharmaceutical Industry. Kellogg School of Management, Northwestern University: U.S., 2004. Disponível em: <http://www.kellogg.northwestern.edu/academic/biotech/articles/ strategicalternatives.pdf >. Acesso em: 14 dez. 2006.

CURRY, B.; GEORGE, K. D. Industrial concentration: a survey. The Journal of Industrial Economics, v. 31, n. 3, p. 203 - 255, Mar. 1983.

DERENGOWSKI, M. G. F.; ROSENBERG, G.; OHAYON, P., D’AVILA, L. A. Inovação na indústria farmacêutica: uma análise sobre o papel das patentes na competitividade das empresas do segmento de medicamentos genéricos. In: SEMINÁRIO LATINO IBEROAMERICANO DE GESTIÓN TECNOLÓGICA, 11. Anais eletrônicos... Salvador: ALTEC, 2005. 1 CD-ROOM.

DiMASI J. A.; HANSEN R. W.; GRABOWSKI H. G. The price of innovation: new estimates of drug development costs. Journal of Health Economics, Netherlands, v. 22. n. 2, p. 151 - 185, Mar. 2003.

FERGUSON G. J., FERGUNSON P. R. Industrial economics: issues and perspectives. 2nd ed. New York: New York University Press, 1994.

FRENKEL, J. Estudo da competitividade de cadeias integradas no Brasil: impactos das zonas de livre comércio. Cadeia: Farmacêutica. Campinas: Unicamp/NEIT, 2002.

O mercado farmacêutico brasileiro: a sua evolução recente, mercados e preços. In: NEGRI B.; Di GIOVANNI G. Brasil: radiografia da saúde. Campinas/SP: UnicampIE/UFRJ, 2001, cap. 5, p. 157 - 174.

GUIMARÃES, E. A. Acumulação e crescimento da firma: um estudo de organização industrial. Rio de Janeiro: Zahar, 1981.

HALL, M.; TIDEMAN, N. Measures of concentration. Journal of the American Statistical Association, Alexandria, USA, v. 62, p. 162 - 168, Mar. 1967.

HASENCLEVER, L. (Coord.). Diagnóstico da indústria farmacêutica brasileira. Rio de Janeiro: Unesco/FUJB/IE-UFRJ, 2002. (Projeto 914BRZ58).

HAY, D. A.; MORRIS D. J. Industrial economics and organization: theory and evidence. New York: Oxford University Press, 1991.

HENDERSON R. Drug industry mergers won't necessarily benefit R\&D. Research Technology Management, Washington, v. 43, n. 4, p. 10-11, Jul./Aug. 2000.

; COCKBURN I. Scale, scope, and spillovers: the determinants of research productivity in drug discovery. The Rand Journal of Economics, Santa Monica, CA, v. 27, n. $1,1996$.

JOSKOW J. Structural indicia: rank-shift analysis as a supplement to concentration ratios. The Review of Economics and Statistics, Cambridge, v. 42, n. 1, p. 113-116, Feb. 1960.

KPMG CONSULTORIA LTDA. Fusões \& aquisições no Brasil: Análise dos anos 90. 2001. Disponível em: <http://www.kpmg.com.br/publicacoes_ias.asp? $\mathrm{ft}=6 \& \mathrm{fx}=14>$. Acesso em: 12 dez. 2007. 
Gerson Rosenberg / Maria da Graça Derengowski Fonseca / Luiz Antonio d' Avila

MAGALHÃES L. C. G.; LEAL J.C; SAFATLE L. P.; AUREA A. P.; TOMICH F. A.; SILVEIRA F. G.; BARBOSA L. C.; CASTRO B. R. Estratégias empresariais de crescimento na indústria farmacêutica brasileira: investimentos, fusões e aquisições, 1998-2002. Rio de Janeiro: Ministério do Planejamento, Orçamento e Gestão/IPEA, 2003. (Texto para Discussão, n. 995).

McKILLOP, T. AstraZeneca's potential megabrands. [s.1.]: IMS HEALTH, 1999.

PENROSE, E. The growth of the firm. 3. ed. Great Britain: Oxford, 1995.

QUEIROZ S. R. R. Estudo da competitividade da indústria brasileira: competitividade da indústria de fármacos. Campinas: Unicamp, 1993.

RÊGO, E. C. L. Políticas de regulação do mercado de medicamentos: a experiência internacional. Revista do BNDES, Rio de Janeiro, v. 7, n. 14, p. 367-400, dez. 2000.

SCHERER F. M. The pharmaceutical industry - prices and progress. The New England Journal of Medicine, London, v. 351, n. 9, p. 927-932, Aug. 2004.

The pharmaceutical industry. In: CULYER, A. J.; NEWHOUSE, J. P. Handbook of health economics. Amsterdam: Elsevier, 2000, chap. 25, p. 1297-1336.

; ROSS, D. Industrial market structure and economic performance. 3. ed. Boston: Houghton Mifflin, 1990.

SCRIP'S 2005 YEARBOOK. $21^{\text {st }}$ ed. London: Vinita Chambore, v. 1, Feb. 2005.

UNIVERSIDADE ESTADUAL DE CAMPINAS. Núcleo de Estudos de Políticas Públicas. O setor saúde e o complexo saúde no Brasil. Campinas: Unicamp/NEPP, 2000. (Caderno, n. 46).

VALENTIM J. Política de medicamentos genéricos: um estudo do caso brasileiro. 2003. 131f. Dissertação (Mestrado em Economia)-Universidade Estadual de Campinas, Campinas, 2003. 